\title{
TITLE:
}

\section{ASCIDIANS FROM THE PALAO ISLANDS. I}

$\operatorname{AUTHOR}(\mathrm{S})$ :

Tokioka, Takasi

\section{CITATION:}

Tokioka, Takasi. ASCIDIANS FROM THE PALAO ISLANDS. I.

PUBLICATIONS OF THE SETO MARINE BIOLOGICAL LABORATORY 1950, 1(3): $115-150$

ISSUE DATE:

1950-10-05

URL:

http://hdl.handle.net/2433/174438

RIGHT: 


\section{ASCIDIANS FROM THE PALAO ISLANDS. I*}

\section{TAKASI TOKIOKA}

With Plates $1 X, X$ and 23 Text-figures

While I was staying at Korōu (Korror) of the Palao Islands from April 1940 to January 1941 as a research associate of the Palao Tropical Biological Station to study the plankton organisms occurring in the waters around the islands, I was much impressed by the abundance of beautiful tropical ascidians in the waters around the islands. So I endeavoured to collect as many different forms as possible during my stay. Most of the specimens were anaesthetized by hydrochJoric procain, fixed with alcohol, and kept in formalin or in alcohol. A part of these specimens were damaged or lost by the earthquake in the end of 1946, but most of them remain still in good condition. The study of this materal was kegun in the end of 1948 , and has embodied the first report presented here.

I express here my hearty thanks to Prof. S. HATAI, director of the Station at that time, for the grant of a seat in the Station. I am very gratef ul to Prof. T. KomaI for his kind guidance and his incessant encouragement. Mr. R. Wada, Mr. S. WADA and other members of the Nan'yō Pearl Company gave me much convenience in collecting the material. The collectors in the Station, Messrs. SingaKI, Sinsato and YaMAKAW constantly helped me in collecting specimens. Hesuus, a Kanakan boy, used to go with me in my search for the ascidians on the reefs. I recollect the kindness of these people with feeling of deep appreciation. I must also record my thanks for the financial aid given by the Ministry of Education for persuing the present study.

\section{Didemnum (Didemnum) patella (GOTTSCHALDT) 1897}

(Fig. 1)

The largest colony measures $85 \mathrm{~mm} \times 55 \mathrm{~mm}$ in extent and $10 \mathrm{~mm}$ in thickness. Surface layer of test contains a small amount of sand grains and minute masses of mud besides many calcareous spicules. Zooids are embedded in this layer. The bottom layer is gelatinous. The lacunae between the surface and the bottom layers

*Contributions from the Seto Marine Biological Laboratory, No. 146.

Publ. Seto Mar. Biol. Lab., I (3) 1950. 
are filled with zoochlorellae which are ca. $20 \mu$ in diameter. Consequently, the test shows a faint greenish tint in life, in preserved specimens the colour fades to yellowish brown. Calcareous spicules spherical ; large ones reach $70 \mu$ in diameter. They are each composed of many rudiating crystals, distal ends of which do not project out from the general contour of the spicule. Smaller ones have several thick rays projecting out from the surface and giving the spicule a spiny appearance.

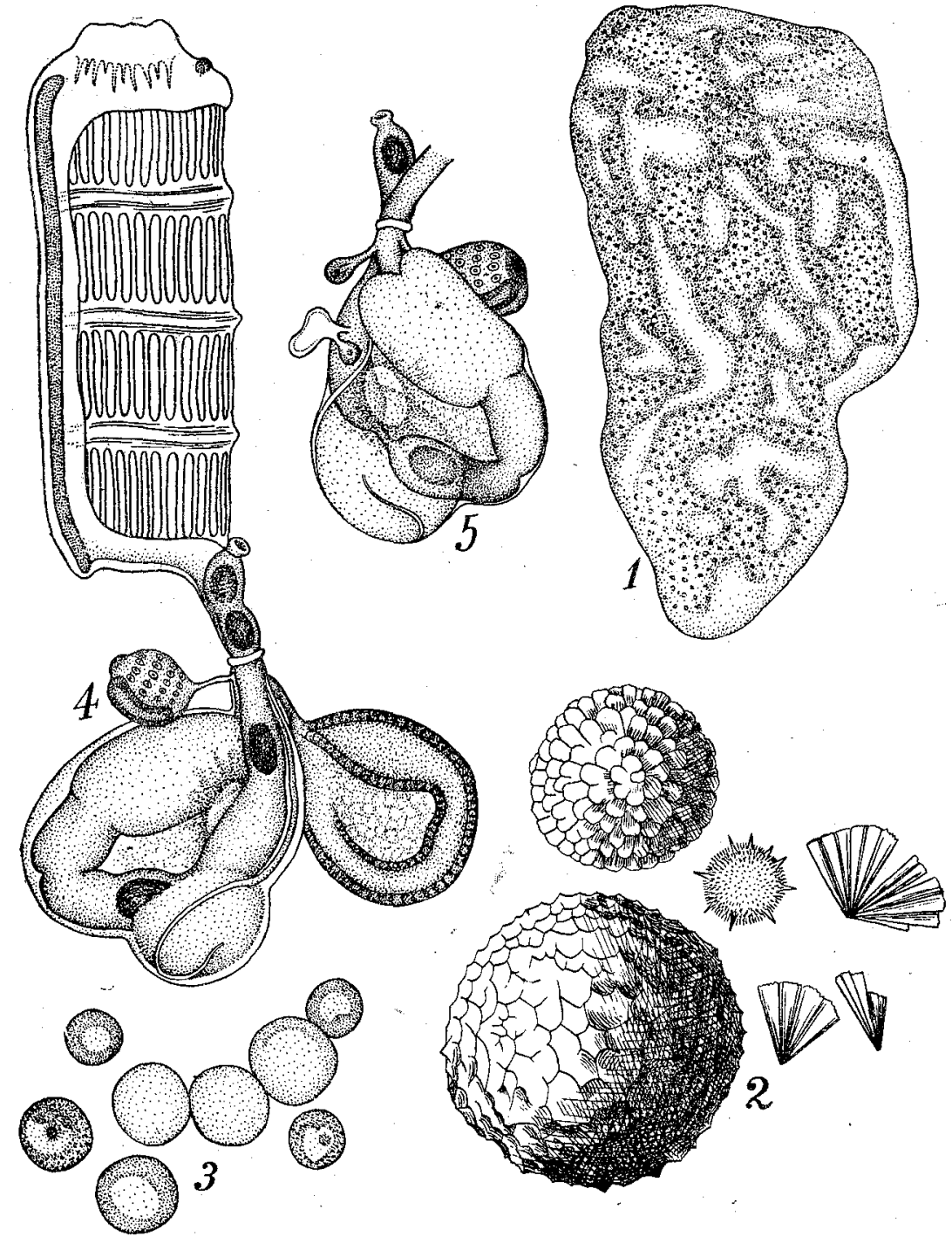

Fig. 1. Didemnum palella (Got tschaldr). 1-Entire colony, $\times 2 / 3 ; 2-$ Calca-

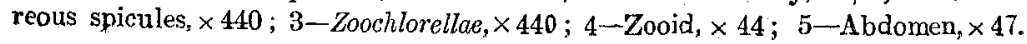


Zooid: Large zooids reaeh $2.4 \mathrm{~mm}$ in length. Thorax very large. Branchial aperture 6-lobed?; atrial aperture a huge opening extending from the dorsal ganglion anteriorly to the posterior end of the thorax posteriorly and near the endostyle ventrally. Consequently, the most part of the branchial sac is naked.

Thorax: Branchial sac with 4 stigmata-rows, each consisting of 12 elongate stigmata. Dorsal languets indistinct on the present material, though they are described on GotTschaldt's specimens to be distinct. Tentacles ca. 15. Ciliated groove minute and oval in outline. Anus situated at the dorso-posterior corner of the thorax and with a thickened lip.

Abdomen: Mid-intestine distinct. Testicular follicle 1; proximal end of vas deferens is curved like a hook, but not coiled. This feature and the shape of the thorax apparently show that the present species, with the following new species and some others, form a group closely relating to Didemnum on one hand and to Lissoclinum on the other. Pericardium on the opposite side of the gonad.

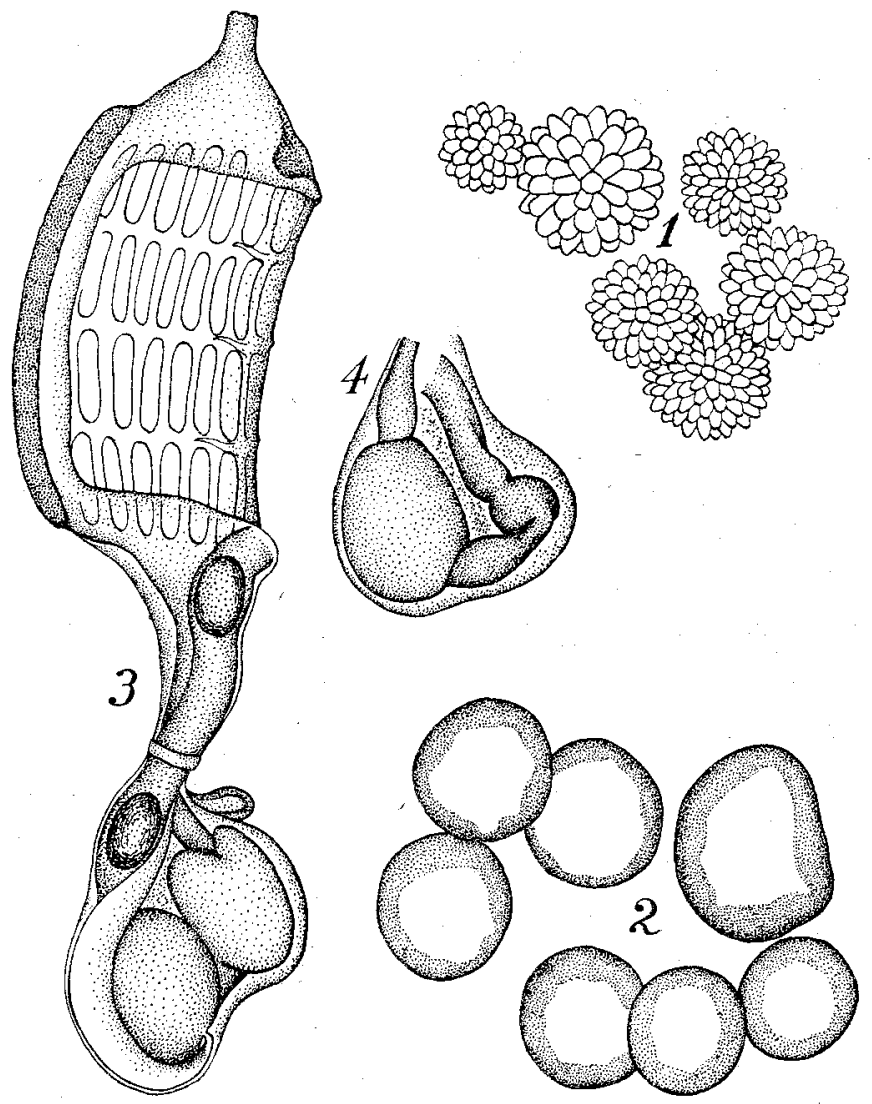

Fig. 2. Didemnum gottschaldti n. sp. 1-Calcareous spicules, $\times 440,2-Z 00-$

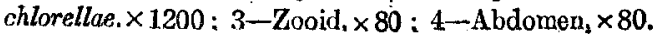




\section{Didemnum (Didemnum) gottschaldti n. sp.}

(Fig. 2)

Many small colonies, measuring $13 \mathrm{~mm} \times 13 \mathrm{~mm} \sim 45 \mathrm{~mm}+18 \mathrm{~mm}$ in extent and $2 \mathrm{~mm}$ in thickness. Several depressions distributed somewhat irregularly on the surface of the colony. In life, they are white as a whole, frequently with faint pinkish and pale bluish green tints in some parts. When the colony is dissected, a bright green colour appears around zooids. This colour is caused by the presence of zoochlorellae in the test, which are 12-17 $\mu$ in diameter and slightly smaller than those in the preceding species. Calcareous spicules are also smaller than in D. patella, being 30-35 $\mu$ in diameter, stellate with many bluntly tipped prominences, and are distributed evenly throughout the test. Lacunae system indiscernible.

Zooid: $1.5 \mathrm{~mm}$. in length. The appearance of the body is exactly the same as in the preceding species. Branchial aperture 6-lobed.

Thorax: About 7 stigmata in each of 4 rows. Dorsal languets distinct. Tentacles 8 , of which 5 are larger than the rest.

Abdomen: Testicular follicle 1. Proximal portion of vas deferens very thick and not coiled or curved.

\section{Eudistoma amplus (SLUITER) 1909}

(Fig. 3)

Six colonies, of which the largest one reaches $80 \mathrm{~mm} \times 100 \mathrm{~mm}$. Thickness up to $12 \mathrm{~mm}$. Oval system, ca. $8 \mathrm{~mm}$ long, recognizable, though with some difficulty, in some colonies. Tissue of test coarse and sponge-like and contains many vacuoles which are filled with many corpuscular bodies and measuring $280 \mu$ in diameter in larger ones. Sand grains and some broken spicules of lower invertebrates are embedded in the surface layer; many faecal pellets are embedded in the bottom layer. Colour in life purplish brown, fading to yellowish brown in alcohol.

Zooid: $8 \mathrm{~mm}$ in length. Abdomen much longer than thorax. Both apertures 6-lobed.

Thorax: Branchial sac with three stigmata-rows, each consisting of ca. 18 elongate stigmata. Tentacles 8, 6 larger and 2 smaller ones. Ciliated groove is an oval orifice. Dorsal languets slender and triangular in shape, not finger-shaped as in many other species. Anus bilobed, and situated on the level between the 2nd and 3rd stigmata-rows.

Abdomen: Oesophagus thin and very long. Stomach found near the posterior end of the body, elongate and smooth-walled. Mid-intestine distinct. Rectum 

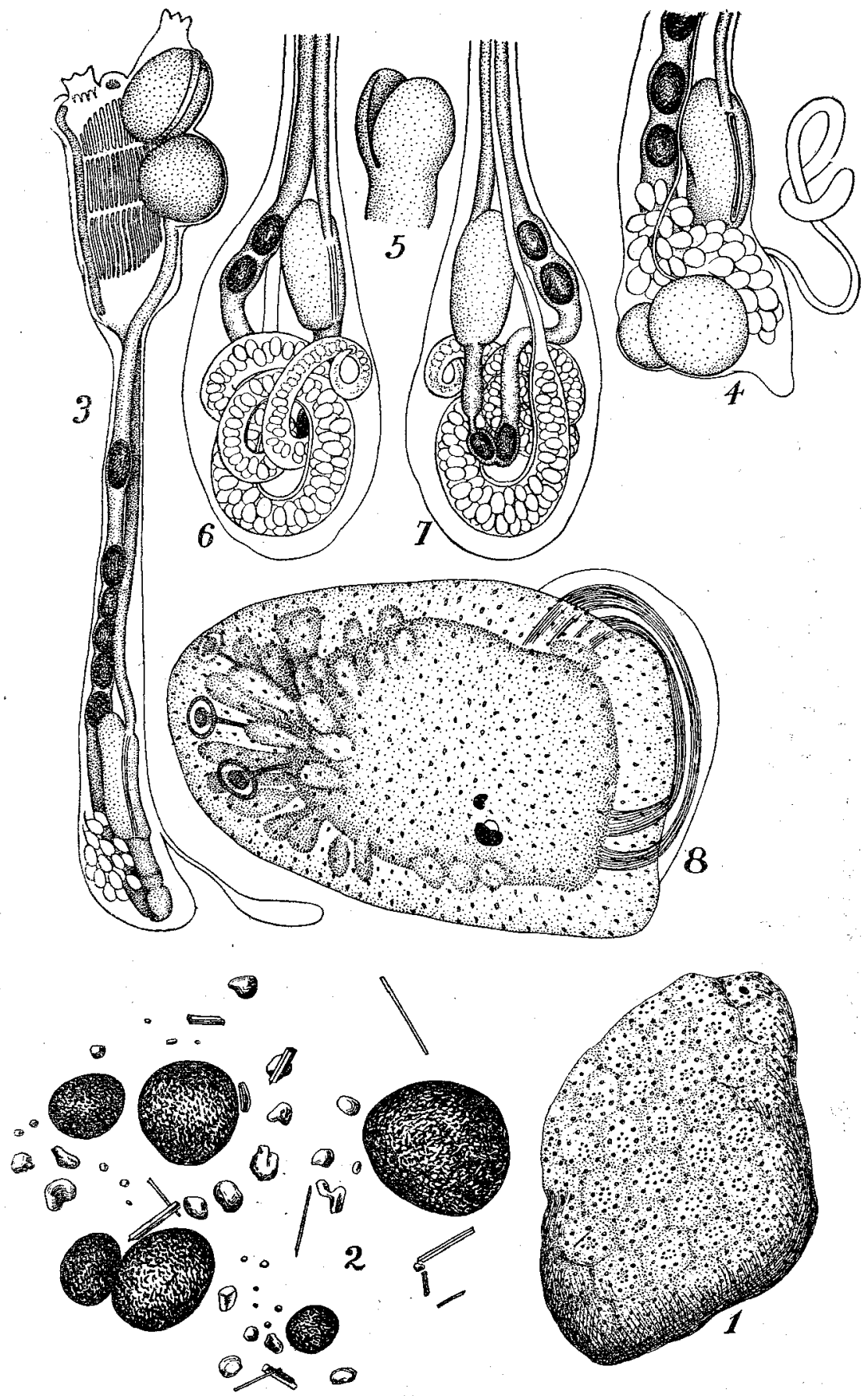

Fig. 3. Eudistoma amplus (SLuITER). 1-Eutire colony, $\times 3 / 5 ; 2-\mathbf{A}$ part of test, $\times 66$; 3-Zooid ; 4-Abdomen; 5-Amus; 6 \& 7-Abdomen with testicular follicles arranged regularly in a long coecum; 8-Larva, $\times 66$, 
without coecum in the proximal portion. A few ova present at the posterior end of the abdomen. Testicular follicles clustered behind the stomach in smaller zooids, while they are arranged regularly in a long coiled coecum in larger zooids. Two or three embryos are found in a brood chamber on the right side of the thorax in some zooids.

\section{Eudistoma pyriforme (HERDMAN) 1886}

(Fig. 4)

oIT. (1) HERDMAN (1886): Challenger Report, Zool., Vol. XIV, pp. 419-420.

(2) Hastings (1931): Great Barrier Reef Expedition, Sci. Rep., Vol. IV, No. 3, pp. $83-85$.

Many colonies, each consisting of a few cormidia. Large cormidium may reach

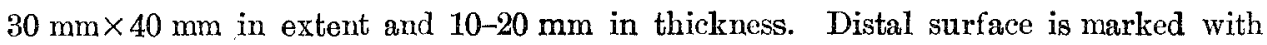
irregularly arranged depressions. System indistinct. Test rather tough, and sandcoloured; it contains many sand grains and yellowish faecal pellets (?).

Zooid: About $10 \mathrm{~mm}$ in length, embedded obliquely in the test when the latter is thin. Both apertures 6-lobed.

Thorax: About 20 longitudinal and 50 transverse muscles on each side of thorax. Stigmata in three rows, each consisting of ca. 20 elougate stigmata. Dorsal languets finger-shaped and displaced slightly to the left side. Tentacles ca. 20, larger and smaller ones alternating rather regularly. The inner surface of the branchial siphon in front of the tentacular ring is distinctly papillated. Ciliated groove small and oval in outline.

Abdomen: Stomach situated near the posterior end of the abdomen, oval in outline and with smooth surface. Mid-intestine distinct. Proximal part of rectum is curved like $\mathrm{S}$ and devoid of any coecum. Anus bilobed, and opens on the level between the 2nd and.3rd stigmata-rows. Testicular follicles clustered behind the stomach. A few ova are present near the centre of the testis. Heart at the posterior end of the abdomen.

\section{Cystodytes dellechiajei (DELLA VALLE) 1877}

(Fig. 5)

Several colonies, the largest one measuring $50 \mathrm{~mm} \times 20 \mathrm{~mm}$ in extent. Thickness of colonies varies from 2 to $5 \mathrm{~mm}$, grayish purple, with white flecks here and there on the surface. Purple pigments are confined to the upper layer containing thoracic segments of zooids. The white flecks are caused by the presence of small calcareous spicules in the superficial layer. The spicules are discoidal in shape, with diameter up to $80 \mu$, and are densely packed in the surface layer in some colonies concealing 


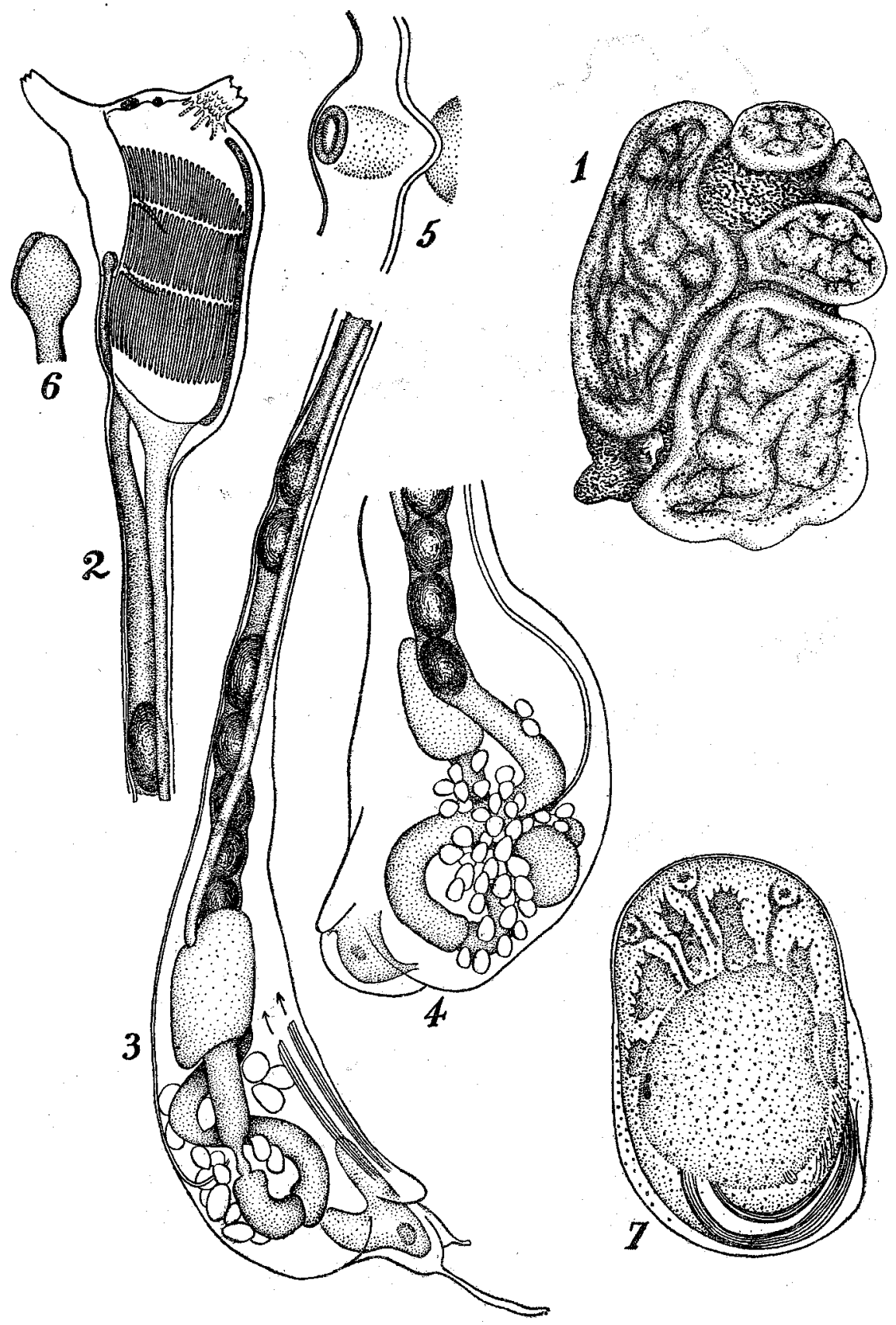

Fig. 4. Eudisloma pyriforme (Herdman). 1-Entire colony, $\times 2 / 3$; 2-Thorax of zooid, $\times 24 ; 3 \& 4$-Abdomen, $\times 24 ; 5$-Ciliated groove, $\times 200 ; 6$-Anus; 7 -Embryo, $\times 80$. 

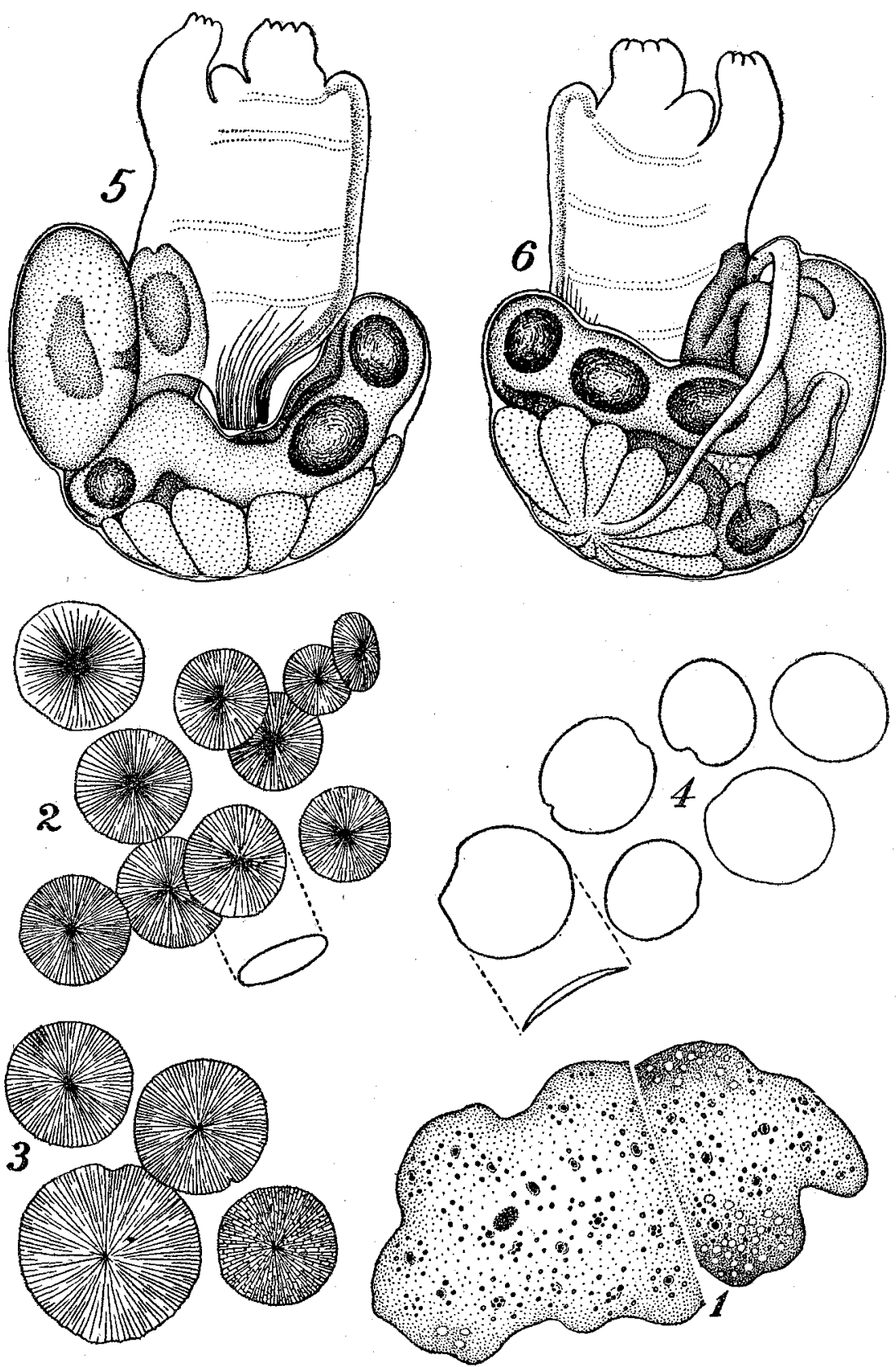

Fig. 5. Cystodytes dellechiajei (Denta VAlLE). 1-Parts of colony, $\times 2 / 3$; 2 4-Calcareous spicules, $(2-$ from superficial layer $\times 200,3-$ from bottom layer $\times 200,4$-from abdominal capsule $\times 24) ; 5 \& 6-Z$ ooid, $\times 47$. 
completely the purple tint caused by pigments beneath them. The lower layer coutaining abdominal segments of zooids is devoid of purple pigments, and has a yellowish-brown tint. This layer contains sparsely discoidal calcareous spicules slightly larger than those in the superficial layer, being $0.11 \mathrm{~mm}$ in diameter. The spicules around the abdominal capsule are larger, being $0.7-0.8 \mathrm{~mm}$ in diameter. The central portion of the spicule is somewhat thickened, but forms no peak. A group of 6-12 zooids surround 1-3 cloacal apertures.

Zooid: $1.5 \mathrm{~mm}$ in length. Branchial aperture 7-lobed; atrial aperture fringed with 6-7 lobes, of which the two frontal ones are most prominent.

Thorax: About 10 stigmata in each of 4 rows. Dorsal languets indistinct. Tentacles 10-12, excluding minute ones. Ciliated groove a small oval orifice. Anus situated on the level between the 3rd and the 4th rows of stigmata and with thickened margin.

Abdomen: Testicular follicles up to 16.

\section{Cystodytes philippinensis HERDMAN 1886}

(Fig. 6)

Several colonies, of which the largest one measures $45 \mathrm{~mm} \times 30 \mathrm{~mm}$ in extent and with thickness $2-3 \mathrm{~mm}$. System indistinct. The upper layer of the colony containing thoracic segments of zooids is transparent, pale purplish, and devoid of calcareous spicule. The lower layer harbouring abdominal segments of zooids is dark purple and contains broken spicules besides some sand grains. Abdominal capsules are composed of large $(0.3 \mathrm{~mm}$ in diameter) disc-shaped spicules and small
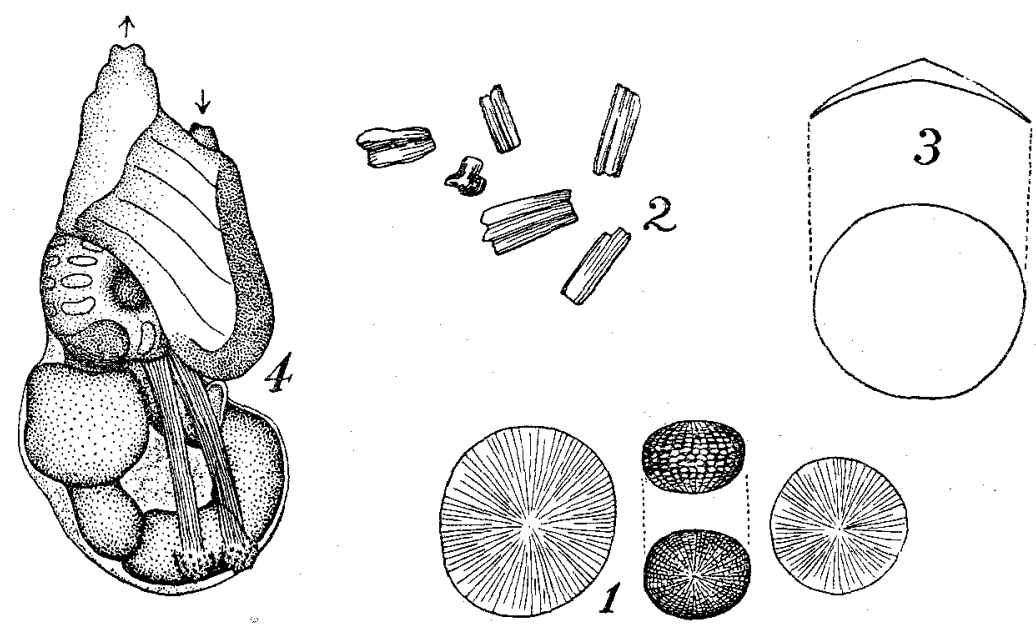

Fig. 6. Cystodytes philippinensis HERDMAN. 1-Small calcareons spicules, $x$ $440: 2-$ Broken spicules, $\times 200: 3$-Large spicules, $\times 73: 4-Z$ Zooid, $\times 47$ 
(less than $40 \mu$ in diameter) spheroidal or discoidal spicules. Large spicules are very thin and brittle; each with central portion forming a peak.

Zooid: $1.2 \mathrm{~mm}$ in length in contracted condition. Gronad not developed in any zooid.

\section{Perophora listeri FORBES and HANLEY 1848}

(Fig. 7, 1-2)

- About 20 individuals, up to $2 \mathrm{~mm}$ long, were collected from the surface of dead coral fragments. Branchial aperture terminal and 8-lobed, atrial aperture slightly anterior to the middle of the body and 6-lobed.

Branchial sac: Branchial sac with 4 rows of stigmata. The number of stigmata are $24-25$ in the first row, 22-23 in the second, 21 in the third and 17-18 in the fourth in one specimen. Interual longitudinal vessels 8-9; those situated near the endostyle and the dorsal lamina are usually represented merely by rows of papillae. Some incomplete vessels may be found in the central portion of the branchial sac in some specimens. About 2 stigmata in a mesh. Tentacles ca. 10, excluding minute ones.

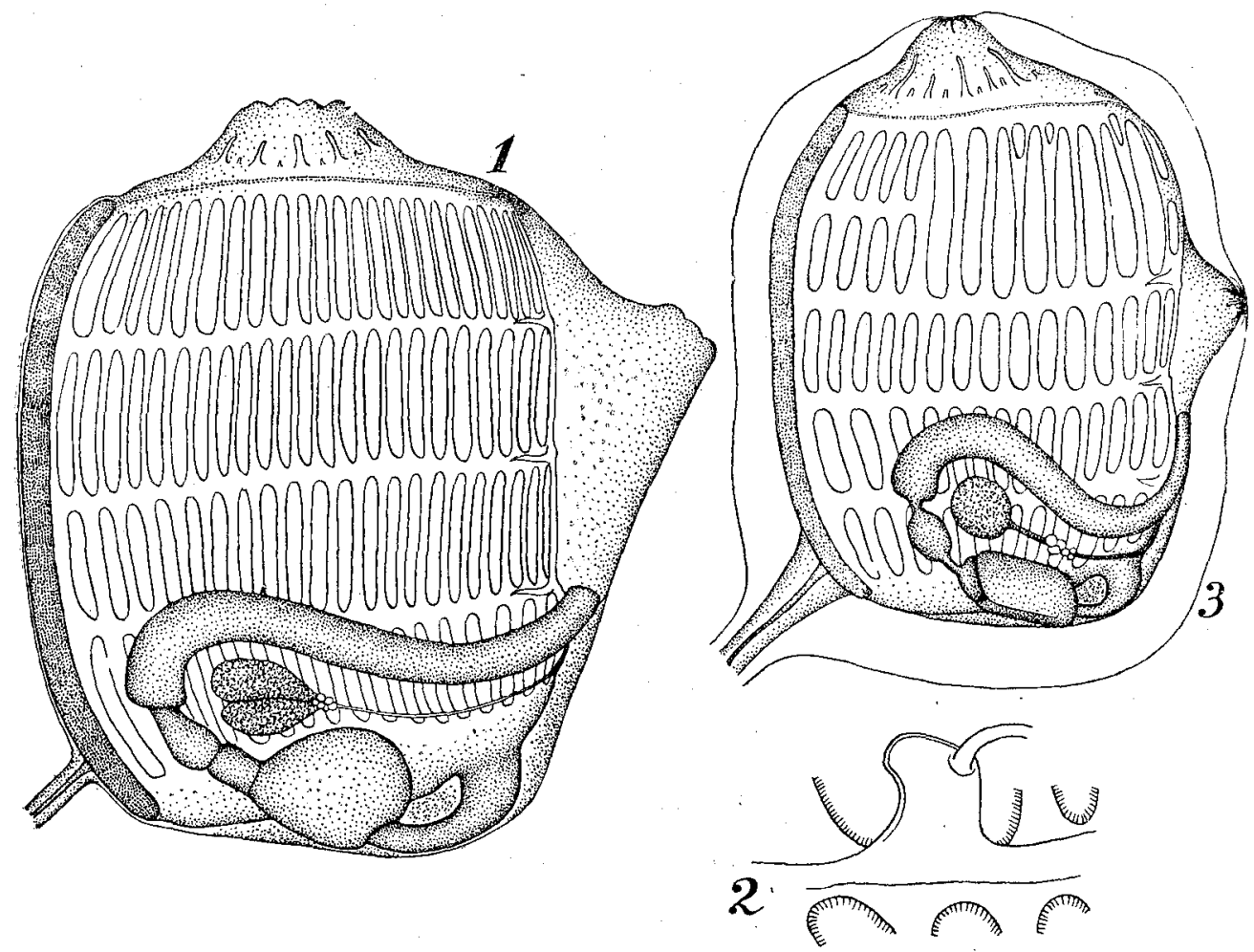

Fig. 7. (1 \& 2) Perophora listeri Fonbes \& HANLEy. (3) Perophora bermudensis Berrill. 1-Left side of the animal; 2-Supporting process of longitudinal vessel, $\times 200$. 
Alimentary system: Intestine is not curved strongly. The anterior end of the intestinal loop reaches slightly beyond the 3rd transverse vessel. Stomach roundish, and without any crest or fold on the wall. Mid-intestine distinct; anal opening on the level of the 3rd transverse vessel and with plain margin.

Gonad: Gonad in the intestinal loop. Testis consists of two lobes; o ary situated at the proximal point of vas deferens.

Colour in life: Body yellow, stomach orange.

Remarks: The European specimens seem to have the intestine curved more strongly than in the present specimens. This difference will need more crucial examination on more materials. The course of the intestine in present specimens reminds us that in Perophora hornelli Herdman, a species known from Ceylon and which is much Jarger $(4 \mathrm{~mm})$ than the present specimens. The exact comparison of the materials is not feasible at present, since HeRDMAN's description on his specimens from Ceylon is too brief and insufficient.

\section{Perophora bermudensis BERRILI 1932}

(Fig. 7, 3)

Three colonies consisting each of about 10 individuals. The largest individual reaches $2.5 \mathrm{~mm}$ in length, althongh most of them are less than $2.2 \mathrm{~mm}$. Branchial aperture terminal and 8-lobed; atrial aperture near the middle of the body.

Branchial sac: With 4 rows of stigmata; stigmata of the first row are very long and bridged transversely near the middle by a parastigmatic vessel and show the tendency to be divided into two stigmata. This division occurs at first in those near the endostyle, then in those near the dorso-median line and at last in nearly all stigmata of the row excepting those situated here and there in the middle portion. The number of stigmata in a small individual is 15 in the first row, 13-15 in the second, $13-14$ in the 3 rd and 12 in the 4 th row, while it is 21 in anterior rows in a larger individual. Internal longitudinal vessels 11-12, of which one or two dorsal vessels are incomplete. Supporting protuberances of the vessel at cross-points are devoid of papilla. Dorsal languets 3 in number; the first transverse vessel lacking the languet. Tentacles number about 20, excluding minute one, and comprise large, medium and small ones; they are usually infected by many Suctorian ciliata.

Alimentary system: Intestine describes a S-shaped course and leads on the level of the middle of the third stigmata-row to the anus showing a plain margin. The anterior end of the intestinal loop reaches near the anterior margin of the 3rd stigmata-row. Stomach elongate and without any crest or fold on the wall; midintestine distinct.

Gonad: Gonar consists of a testicular mass located in the first intestinal loop, and several ova attached onto the sperm duct at some distance from the testis. 
Colour in life: Nearly colourless to yellow. Stomach orange. Dark greenish tint around the intestinal loop in some individuals.

\section{Ecteinascidia sluiteri HERDMAN 1909}

(Fig. 8)

Many individuals up to $9 \mathrm{~mm}$ in length. Body elongate-oval, attached to stolon at the postero-ventral corner of the body. Both apertures 7-9 lobed; the branchial terminal and the atrial about one-third of the body length from the anterior end of the body. Test transparent, sometimes covered with hydroids, etc. Many transverse muscles on the mantle are divided into three longitudinal groups, one on the dorsal side behind the atrial aperture and the other, one on each lateral side of the body.

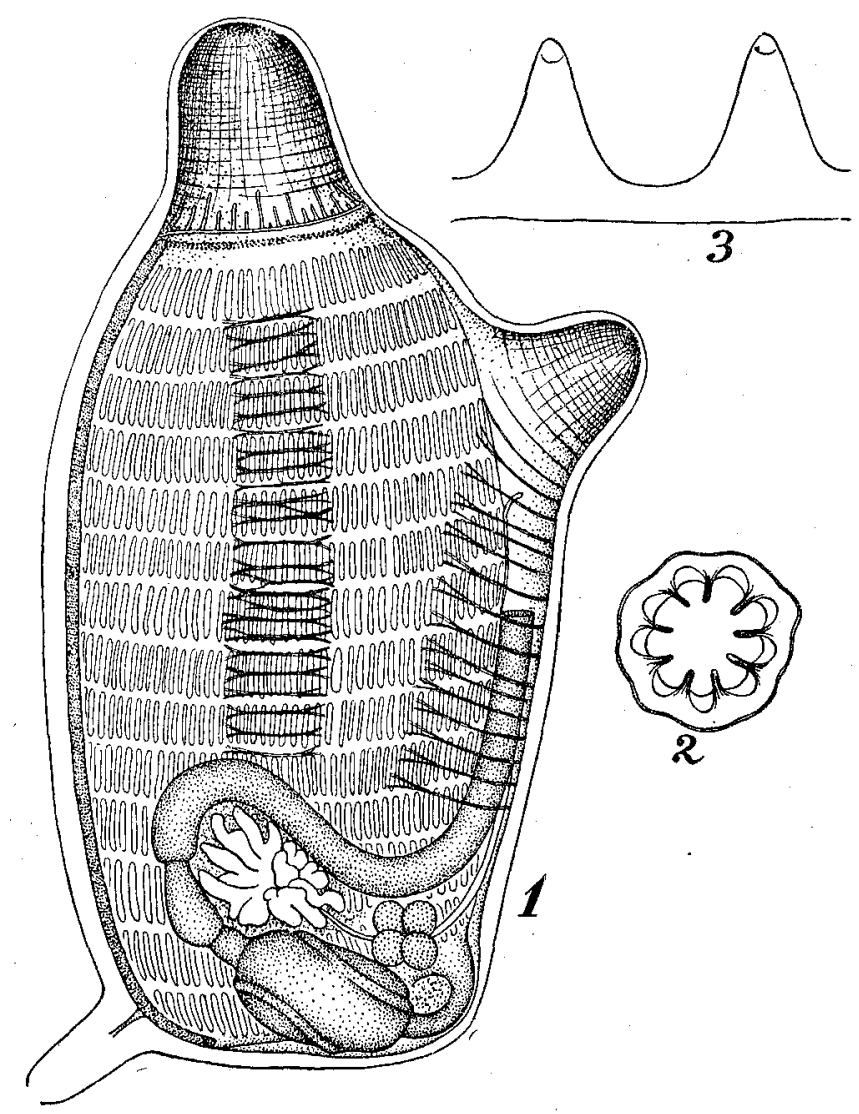

Fig. 8. Ecteinascidia sluiteri Herdman. 1-Left side of the animal, 2-Atrial aperture from insicle, 3-Supporting processes of longitudinal ressels. 
Branchial sac: 14 rows of stigmata on the left side, and 14-15 rows on the right side. About 45 stigmata in a row. Inner longitudinal vessels 20-23, of which the dorsal one or two are incomplete. About 2 stigmata in a mesh. Parastigmatic vessel absent. Tentacles about 50, of which nearly one-half are small or minute. Ciliated groove a small round orifice.

Alimentary system: Intestine S-shaped. The anterior end of the intestinal loop reaches the anterior end of the 10th stigmata-row. Anus situated on the level of 7-8th transverse vessel and with plain margin. Stomach elongate-oval, with 5 more or less spiral crests; mid-intestine distinct.

Gonad: Testis composed of several ramified lobes situated in the first intestinal loop. A few ova attached to the sperm duct considerably apart from the testis. Sperm duct opens to the atrial cavity on the level of the 5th transverse vessel.

Colour in life: Almost colourless to yellow or faint orange. Stomach orange.

Remarks: The difference between Herdman's original specimens from Ceylon and the present specimens from the Palao Islands lies in the number of tentacles which are only 20 in Ceylon specimens. This number, however, is apparently given only for larger tentacles, and that of small or minute tentacles are not included.

\section{Ecteinascidia hataii n. sp.}

(Fig. 9, 1-2)

Three individuals, up to $10 \mathrm{~mm}$ in length, Body ovate, lying on the substratum by its ventro-sinistral side. Test soft and transparent, with many minute foreign matters on the surface. Both apertures faintly 6-lobed. Branchial aperture terminal, the atrial apart from the branchial about $1 / 3$ of the body length. Mantle provided with ca. 40 transverse muscles on the dorsal side behind the atrial aperture, of which those on the posterior half are cut at dorso-median line. Many minute whitish spots scattered on the whole surface of the mantle.

Branchial sac: 16 (rarely 15) rows of stigmata are present, each consisting of 45-50 stigmata. Inner longitudinal vessels are 21-22, consequently 2-3 stigmata in a mesh. Supporting processes of inner longitudinal vessels are curved dorsad. Tentacles very long; ca. 20 in number, excluding minute ones. Ciliated groove a small round opening.

Alimentary system: Intestine curved very slightly. Stomach ovate and with $\mathbf{5}$ spiral crests; its posterior half behind the branchial sac. Mid-intestine discernible, though not very distinct. Anus situated on the level between the 6 th and 7 th rows of stigmata and plainly margined.

Gonad: In wide intestinal loop. Testis consisting of ramified branches; ovary at the proximal point of vas deferens.

Colour in life: Colourless except the stomach and the proximal portion of rectum being coloured orange. 

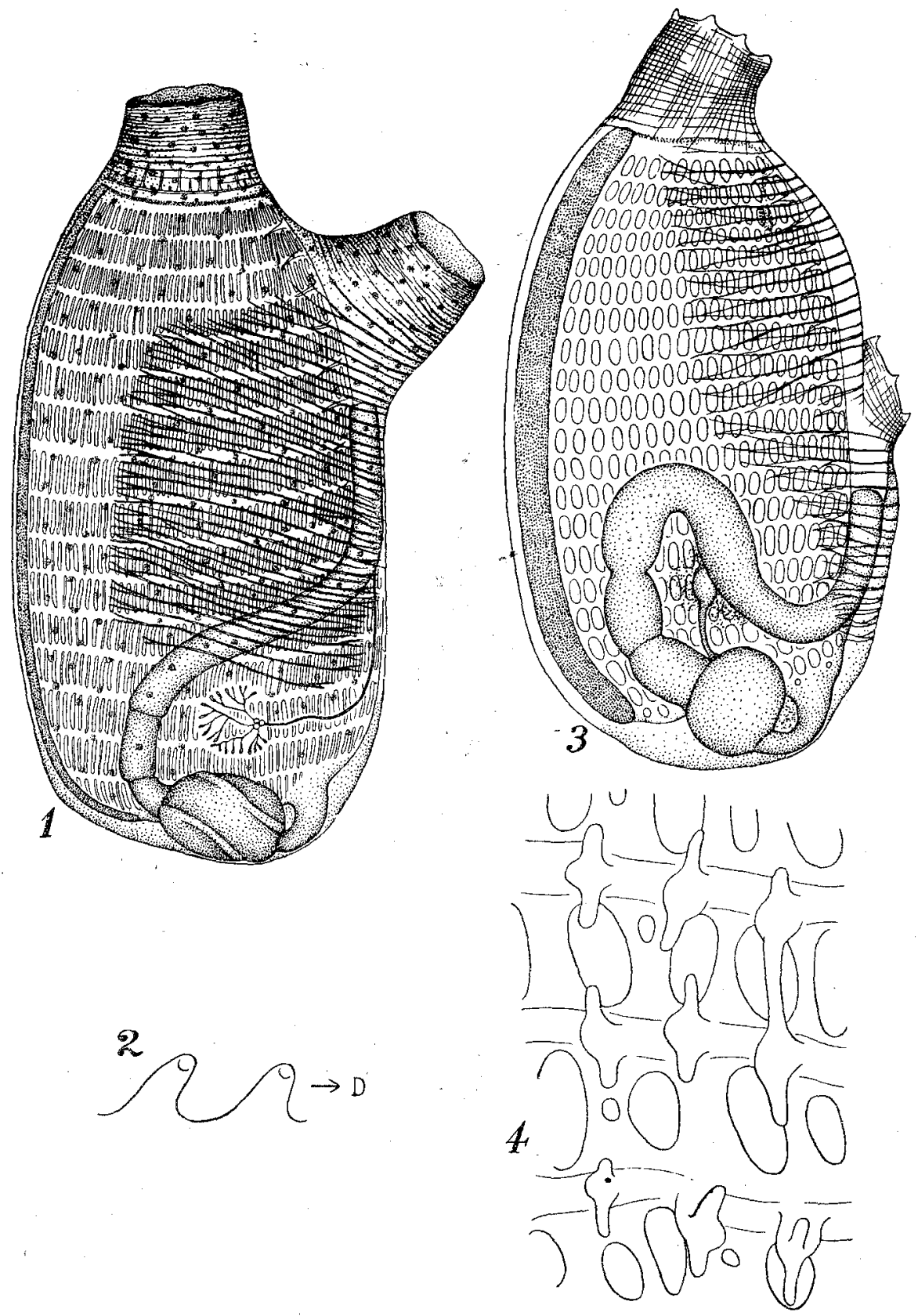

Fig. 9. 1 \& 2 Ecteinascidia hataii n. sp. 1-Left side of the animal, 2Supporting processes of longitudinal vessels. 3 \& 4 Ecteinascidia imperfecta D. sp. 3-Ieft side of the animal, $\times 35 ; 4-\mathrm{A}$ part of the branchial sac, $\times 200$. 


\section{Ecteinascidia imperfecta n. sp.}

(Fig. 9, 3-4)

A single individual was found among the specimens of Ascidia minuta. Body elongate-oval, attached to the stolon. Branchial aperture terminal, 8-lobed, and slightly bending dorsally. Atrial aperture at nearly the middle of the body, 7-lobed and bending slightly to the right side. The animal is $2.5 \mathrm{~mm}$ long in mantle specimen. Test thin, transparent, and free from foreign matters. Many transverse muscles on the dorsal half of the mantle on the left side and on the whole surface on the right side.

Branchial sac: With 21 rows of stigmata. Dorsal lamina consists of a row of dorsal languets as in the preceding species. About 20 rows of papillae, bearing each a short anterior and a short posterior prominences which are parts of a rudimentary longitudinal vessel. One to two stigmata in a mesh. Tentacles 18, excluding minute ones. Ciliated groove a small oval opening.

Alimentary system: Intestine S-shaped. The anterior end of the intestinal Joop reaches the 12th stigmata-row. Anus at the 13th transverse vessel and plainly margined. Stomach round, and quite smooth on its surface. Mid-intestine distinct. Gonad not yet developed.

Colour in life: Body yellowish, stomach and a part of intestine orange-coloured.

Remarks: At first I thought this specimen to be a young individual of Ascidia minuta, but the mode of attachment by stolon, the appearance of siphons, and the alimentary canal being provided with distinct mid-intestine seem to differentiate this form from Ascidia, and to refer it to Ecteinascidia. This species closely resembles E. tortugensis PLOUGI \& Jones which has, however, 18 stigmata-rows instead of 21. The imperfect appearance of the inner longitudinal vessels of the branchial sac is the most striking charanteristic of this new species.

\section{Ascidia minuta n. sp.}

(Fig. 10; P1. IX, Fig. 1)

Many specimens up to $9 \mathrm{~mm}$ in length, attached to the substratum by their ventro-sinistral side and crowded together rather densely, although it is doubtful if they have any organic connections with one another. Body rather elongate. Branchial aperture terminal; atrial aperture at the middle of the body. In an abnormal individual the branchial siphon is slightly longer than the body behind the tentacular ring. Test very soft and traneparent, frequently covered with mud which is arranged in several irregular rows. Mantle yellowish-orange. About 45 transverse muscles on the dorsal half of the right side. Branchial aperture fringed with 9-16 lobules; the atrial with 9-12 ones. 

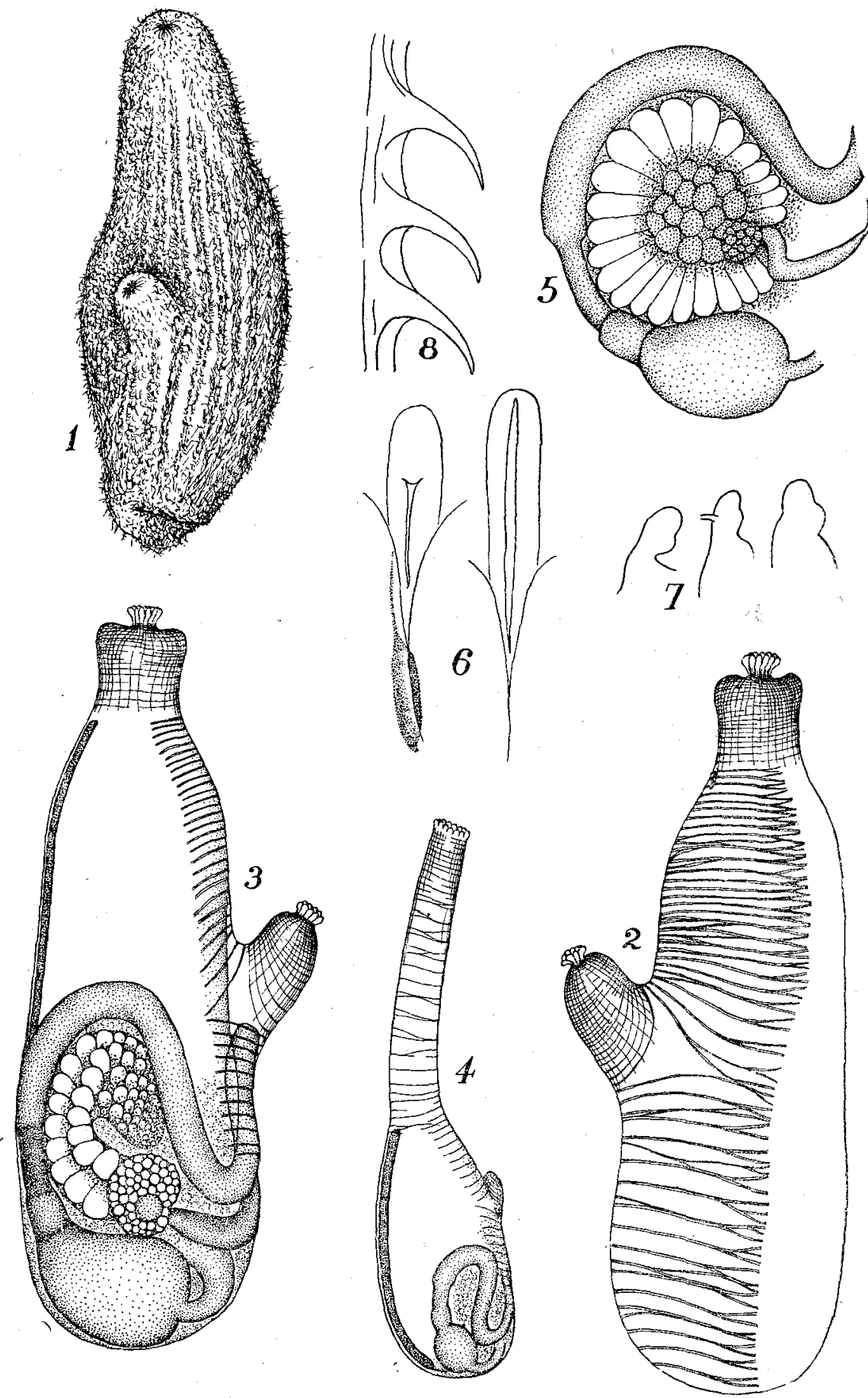

Fig. 10. Ascidia minuta n. sp. 1-Entire animal; 2-Right side of the mantle body; 3-Teft side of the mantle body; 4-Abnormal individual with extremely long branchial siphon; 5 -First intestinal loop with fully matured goned in it ; 6-Ciliated groove ; 7-Supporting processes of longitudinal vessels, $\times 72 ; 8$-Dorsal lamina. 
Branchial sac: With 22-24 rows of stigmata and 20-25 inner longitudinal vessels which have distinct papilla at each cross-point with the transverse vessel, 1 or $11 / 2$ stigmata being in a mesh. Dorsal lamina a low ridge with ribs, the tips of which project out prominently. Ciliated groove a longitudinal groove. Tentacles ca. 20, excluding minute ones.

Alimentary system: The anterior margin of the intestinal loop never reaches beyond the base of the atrial siphon. The first intestinal loop is not quite so wide in immature individuals as in mature ones. Axis of the second intestinal loop $(\alpha)$ passing through the front of the cardiac end if the stomach. Stomach globular; mid-intestine faintly discernible; anus plainly margined. The last course of the rectum located on the right side.

Gonad: Ovary occupies originally the proximal portion of vas deferens, but later transferred to the centre of the first intestinal loop, and surrounded by testicular follicles. Some specimens contain several larvae in their atrial cavities.

Colour in life: Usually yellowish with orange tint on stomach and on some parts of the intestine. Some specimens are olive-brown or somewhat blackish.

Remarks: This species superficially resembles As, archaia SLuITER, a small species from the Bay of Batavia. The latter differs from the former in having the second intestinal loop much rarrower and with $\alpha$-line passing near the pyloric portion of the stomach and in having 3 stigmata in a mesh and a round horse-shoe-shaped ciliatel groove. Both species show some intermediate charateristics between Ascidia and Ecteinascidia.

\section{Ascidia gemmata SLUITER 1895}

(Fig. 11; PI. IX, Fig. 2)

Many specimens up to $50 \mathrm{~mm}$ long $\times 22 \mathrm{~mm}$ wide. Body attached to the substratum by its whole left side. Branchial aperture terminal, siphon projecting out considerably; atrial aperture near the posterior end of the body. Test of a moderate thickness, cartilaginous and transparent. Surface smooth at a glance, although sparsely scattered with minute papillae. Mantle very delicate. Branchial siphon terminating in 12 lobules. Atrial siphon situated at about one-third from the posterior end of the body and directed posteriorly in many cases; it is short and terminates. in 6-7 lobules.

Branchial sac: Inner longitudinal vessels ca. 40. Transverse vessels ca. 120,

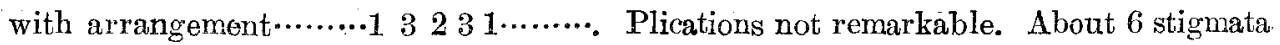
in a mesh. Dorsal lanina with terminally projecting out ribs. Ciliated groove simplew-shaped in small individuals, divided into $2-3$ parts in large individuals. Distance between the peripharyngeal band and the dorsal ganglion about one and a. half times the length of the ganglion. Tentacles 35-50 excluding minute ones. Prebranchial area papillated. 


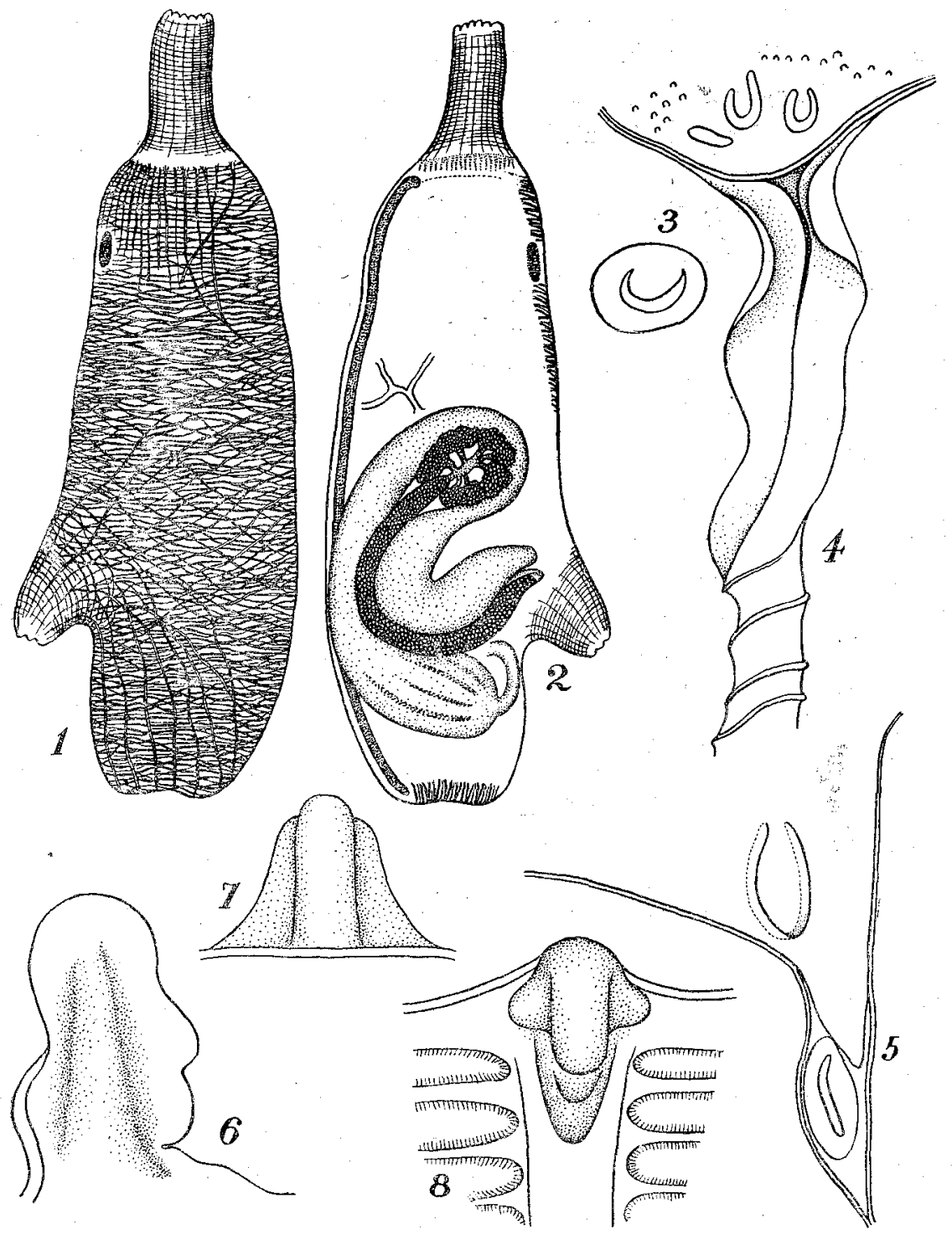

Fig. 11. Ascidia gemmata SLurTer. 1-Right side of the mantle body; 2Left side of the mantle body; $3-5$-Ciliated grooves ( $323-35 \mathrm{~mm}$ long individuals. $440 \mathrm{~mm}$ long individual, $\times 24,550 \mathrm{~mm}$ long individual, $\times 24) ; 6-8$ Supporting process of longitudinal resel ( 6 lateral side, $\times 200,7$ ventral view, 8 top view).

Alimentary system: Atrial siphon near the middle of the visceral mass. First intestinal loop elongate, and bending antero-dorsally. Second intestinal loop surrounded by a thick rectum. Its axis passes behind the pyloric end of stomach. Antis plainly margined. Gonads in the first intestinal loop. 
Colour in life: The anterior half of the mantle body, in some specimens the whole body, is coloured in beautiful red. Margin of branchial aperture yellow. Ovary and oviduct are bluish.

\section{Ascidia sydneiensis STIMPSON 1855}

(Fig. 12; PI. IX, Fig. 3)

A specimen of $52 \mathrm{~mm}$ long $\times 20 \mathrm{~mm}$ wide. Test cartilaginous, transparent, and on the surface with many minute and slender prominiences fumished wi h a few papillae and ciliary processes, and adhering sand-grains or mud masses. Branchial siphon long; atrial aperture slightly posterior to the middle of the body. Mautle brownish. Muscles arranged characteristically along the marginal portion. on the right side.

Branchial sac: Plication absent. About 5 stigmata in a mesh. Dorsal lamina as in the preceding species. Ciliated groove U-shaped. Distance between the clorsaI ganglion and the dorsal tubercle is about one and a half times the length of the former. Tentacles ca. 100. Prebranchial area papillated.

Alimentary system: As in the preceding species. The axis of the second intestinal loop passes through the pyloric portion of the stomach. The swelling of the rectum around the 2 nd loop shown in the figure, seems to be an artefact.

\section{Phallusia julinea SLUITER 1919}

(Fig. 13 ; Pl. IX, Fig. 4)

Many specimens, up to $75 \mathrm{~mm}$ in body length, attached to the substratum by the whole left side. Atrial aperture on a short prominence near the middle of the koty. Test thick, cartilaginous and containing many vessels, of which the terminal ones end in a cromplex ramification. In life, these vessels are filled with yellow pigment-corpuscles and give the animal a beautiful yellowish colour. Surface of test free from foreign matter, granulated very faintly and sparsely. The connecting vessel between the test and the mantle is very firm. Mantle thin, delicate and transparent. Muscles extremely weak. Atrial siphon of considerable length, opening near the middle of the body. Branchial aperture 9-10-lobed; atrial aperture 9-16 ( $=8 \times 2$ ?)-lobed. Margin of each lobe with pectination.

Branchial sao: Plications present, though rather indistinct. About 6 stigmata in a mesh. Dorsal lamina a broad membrane with ribs slightly projecting out from the margin. Dorsal ganglion near the base of atrial siphon. Ciliated groove Uor complex U-shaped. Secondary tubercles 7-19 in number, with simple ciliated grooves. Prebranchial area papillated. Tentaeles $60-80$, excluding a few minute ones, 


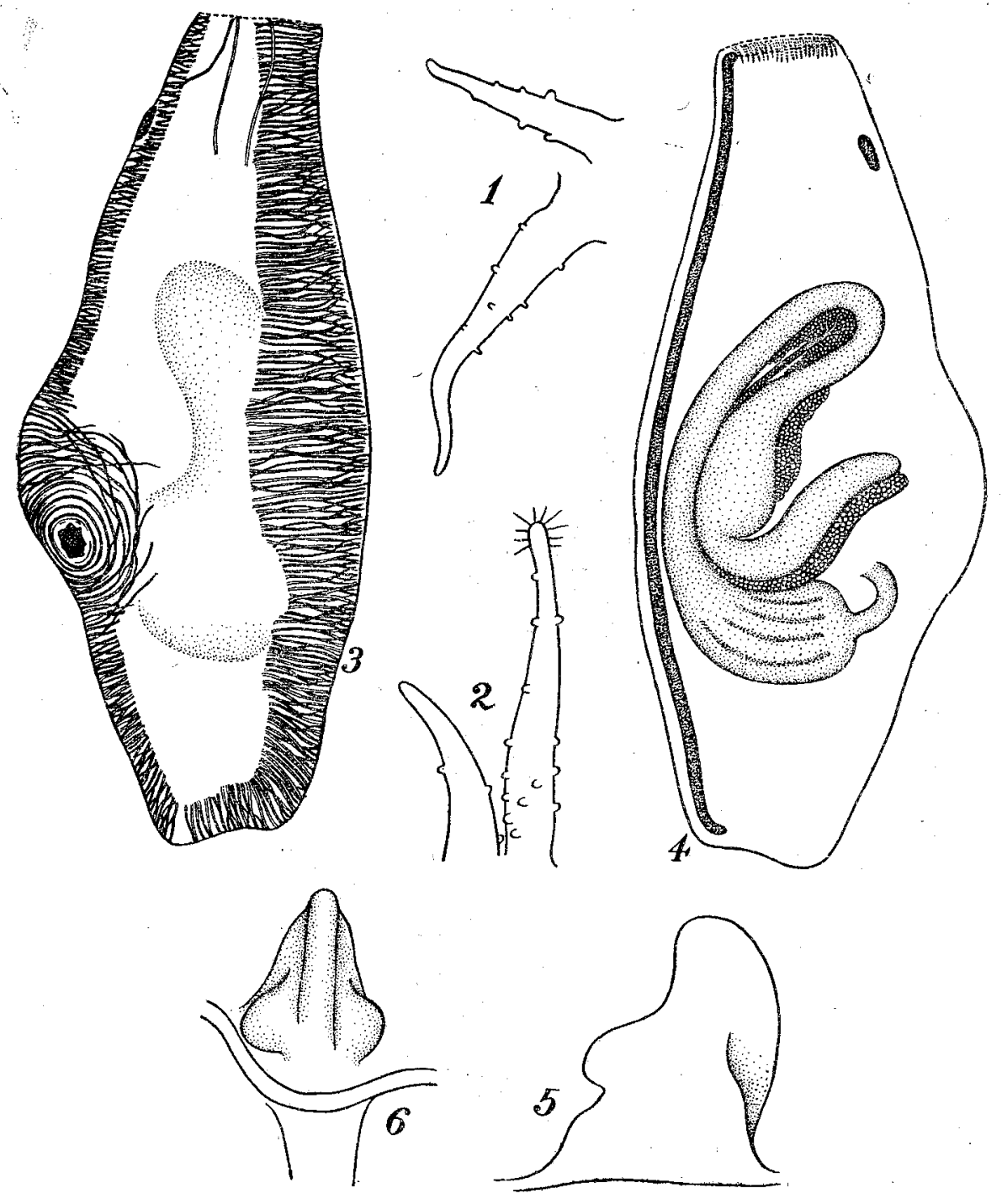

Fig. 12. Ascidia sydneiensis Stimpson. 1 \& 2-Slender prominences on test, $\times 80 ; 3$-Right side of the mantle body; 4-Left side of the mantle body; $5-$ A supporting process of longitudinal vessel, $\times 200 ; 6-$ Top view of $5, \times 200$. 

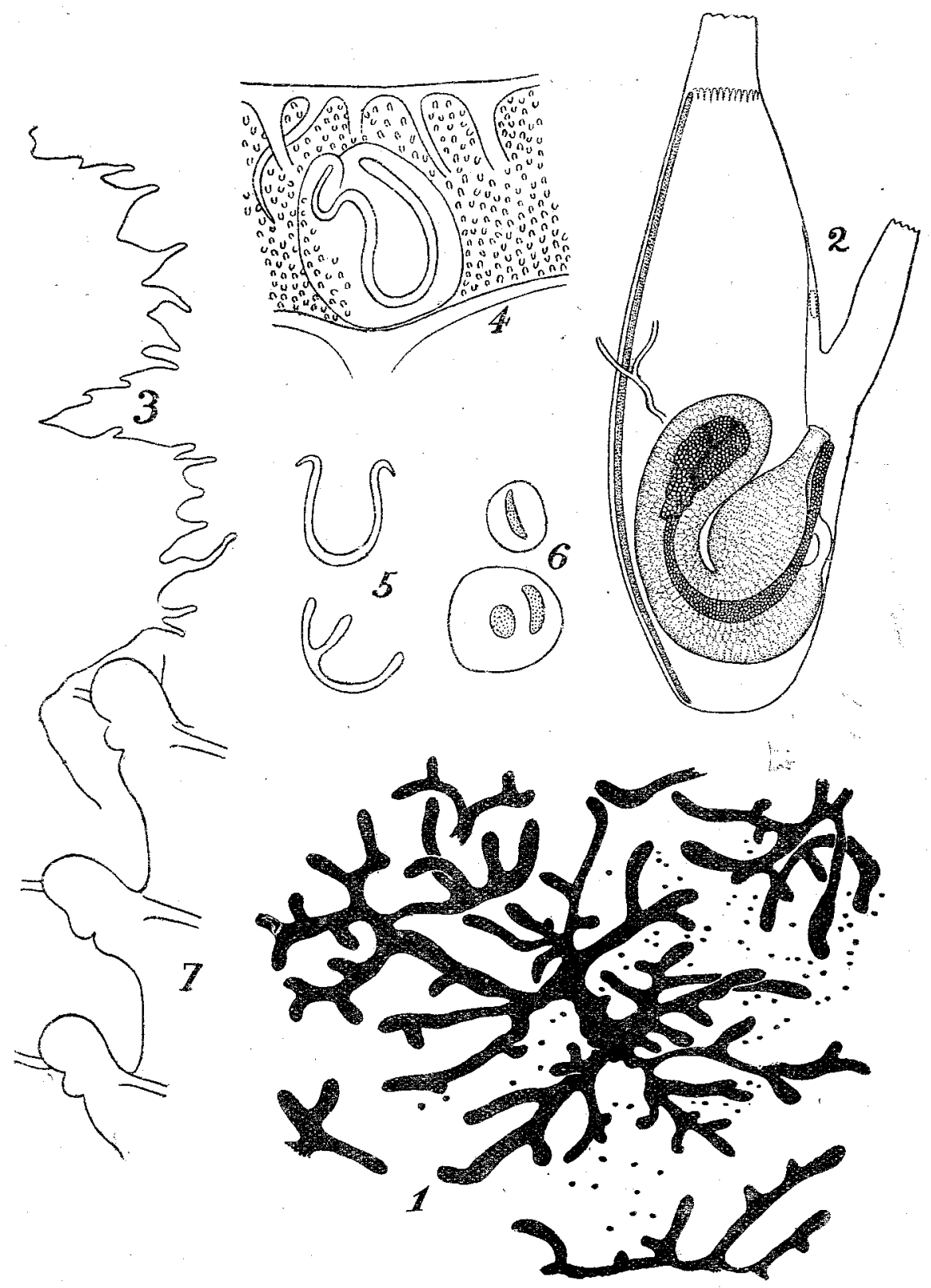

Fig. 13. Phallusia julinea Sturter. 1-Ramification of vessels in the test, $\times$ 47 ; 2-Left side of the mantle body; 3--Pectination of atrial lobules, $\times 47 ; 4 \&$ 5 -Ciliated grooves, $\times 24 ; 6$-Secondary dorsal tubercles, $\times 80$. 
Alimentary system: Anterior margin of intestinal loop does not reach beyond the level of the base of the atrial siphon. Axis of the second intestinal loop passes behind the stomach. Rectum swells conspicuously in the proximal part of its last course. Anus plainly margined.

Gonad: As in many common species of Ascidia.

\section{Polycarpa captiosa (SLUITER) 1885}

(Fig. 14; Pl. X, Fig. 1)

Many specimens, up to $120 \mathrm{~mm}$ in length, were collected in Iwayama Bay from the depth of about 1-2 m. Body cylindrical, attached to the coral rock by its ventral side. Branchial aperture terminal; atrial aperture opens on a prominence near the mid dle of the body. Both apertures 4-lobed. Test leathery and 2-3 $\mathrm{mm}$ in thickness, with surface divided into many parts by grooves as in the test of Styela plicata. It is reddish in life, which colour fades to whitish brown in specimens preserved in formalin. Inner surface glistening pale yellow. Mantle thin and yellowish-brown in preserved specimens, although it is carmin in life. It projects out into a small knob at the position of the dorsal ganglion. Many endocarps are found on the inner surface of the mantle.

Branchial sac: Longitudinal vessels are arranged as follows:

Specimen 1 (110 $\mathrm{mm}$ long)

$\begin{array}{lllllllllllll}\text { left } & \ldots \ldots \ldots \ldots \ldots & \text { D. } & 4 & (25) & 7 & (24) & 7 & (26) & 9 & (20) & 8 & \text { V. } \\ \text { right } & \ldots \ldots \ldots \ldots & \text { D. } & 2 & (26) & 4 & (21) & 7 & (22) & 7 & (15) & 9 & \text { V. }\end{array}$

Specimen 2 (80 $\mathrm{mm}$ long)

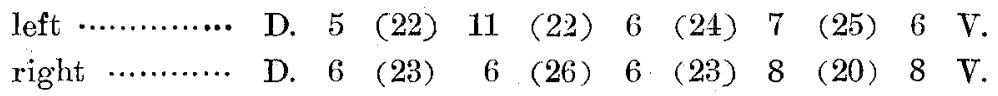

Transverse vessels are arranged in the central part of the branchial sac in the scheme :-..large-small-medium-small-large... Parastigmatic vessels are found abundantly in the posterior part of the sac. Stigmata very long; 7-8 12 stigmata in a mesh. Tentacles 20-30, excluding several minute ones. Dorsal tubercle large ; ciliated groove simple $\mathrm{U}$-shaped in small $(40-50 \mathrm{~mm}$ long) individuals, while it is of a somewhat complex configuration in large specimens.

Alimentary system: Alimentary canal situated in the posterior portion. Striations on the stomach very faint. Margin of anus finely cut into many lobules.

Gonad: Number of gonads varies considerably according to the size of individuals, for instance, a $110 \mathrm{~mm}$ long individual has $\mathbf{5 3}$ gonads on the right side and 46 on the left side, while a $50 \mathrm{~mm}$ long individual has only 11 on the right and 14 on the left side. Gonads are arranged roughly in a row near the dorsal margin on 


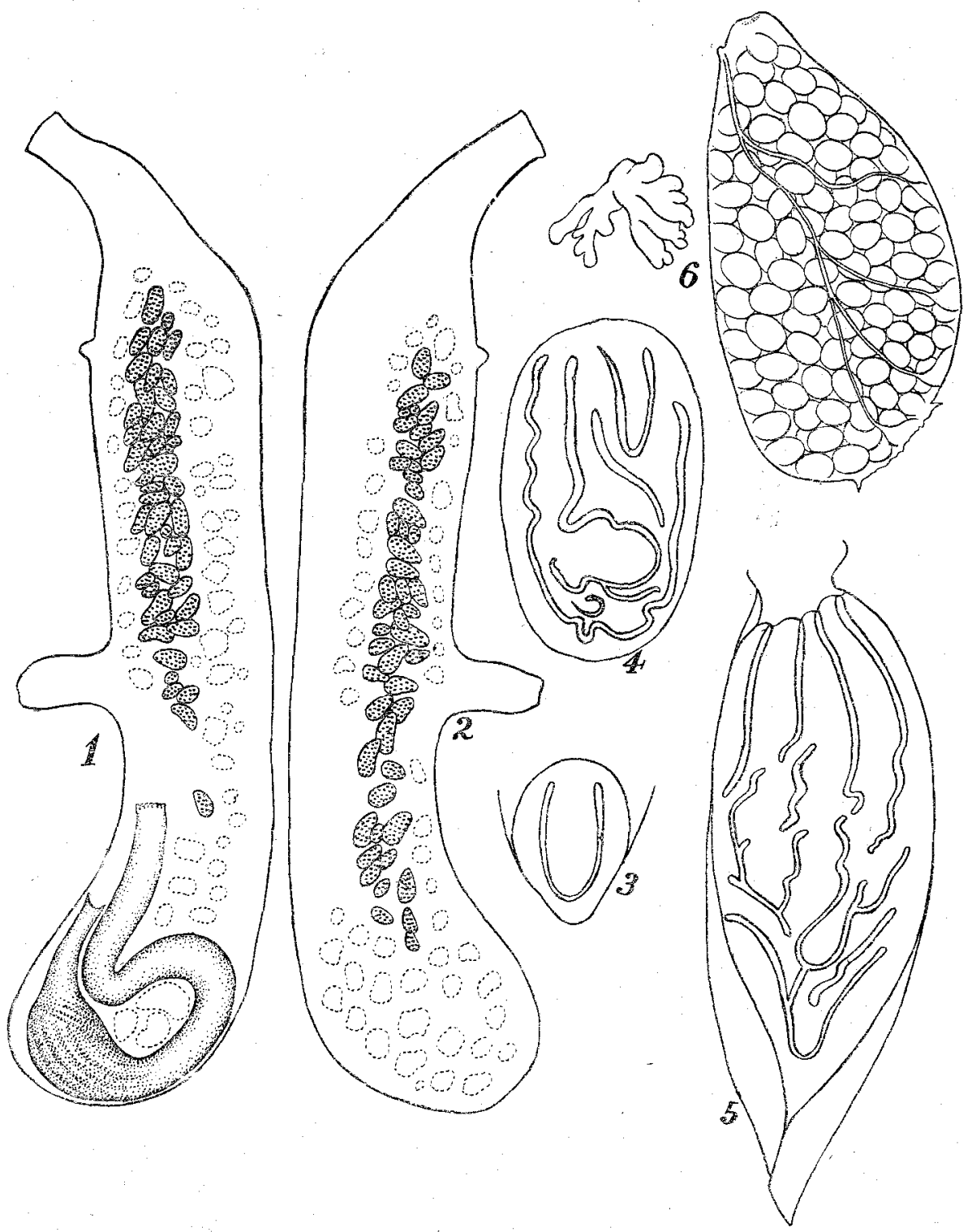

"Wig. 14. Polycarpa captiosa (SLUITER). 1-Left half from inside; 2-Right half from inside; 3-5-Ciliated grooves $(350 \mathrm{~mm}$ long individual, $480 \mathrm{~mm}$ long indivielual, $5110 \mathrm{~mm}$ long individual, $\times 16$ ); $6-$ Goned, $\times 18$.

each side. Each gonad provided with ca. 4 testicular follicles on one iside; each follicle is cut into many lobules.

Remarks: SLurTER's original specimen was apparently a small young specimen of this species, measuring $55 \mathrm{~mm}$ in length and provided with 40 tentacles and a 
ciliated groove much longer than in the small Palao specimens. In the appearance of the body and the general appearance of the alimentary canal, however, his specimen is identical to the Palao specimens.

\section{Polycarpa simplex n. sp.}

(Fig. 15)

Body elongate, slightly depressed dorso-ventrally and attached to the substratum by its ventral surface. It is usually ca. $25 \mathrm{~mm}$ in length, although it may reach $35 \mathrm{~mm}$ long $\times 8-9 \mathrm{~mm}$ wide. Branchial aperture terminal, and facing towards the dorsal side; atrial aperture near the middle of the body, or slightly posterior to that. Test leathery, but not so thick. It is dark red in life, and provided with several longitudinal grooves on the surface. This colour fades into yellowish-white in specimens preserved in alcohol. Mantle adheres firmly to the test, and cannot be taken out of the test.

Branchial sac: Longitudinal vessels arranged as follows:

Specimen 1 ( $35 \mathrm{~mm}$ long.)

$\begin{array}{lllllllllllll}\text { left } & \ldots \ldots \ldots \ldots & \text { D. } & 4 & (12) & 5 & (14) & 4 & (17) & 3 & \text { (13) } & 4 & \text { V. } \\ \text { right } & \ldots \ldots \ldots & \text { D. } & 2 & \text { (18) } & 3 & \text { (15) } & 4 & \text { (16) } & 4 & \text { (11) } & 3 & \text { V. }\end{array}$

Specimen 2 (25 mm long)

$\begin{array}{lllllllllllll}\text { left } & \cdots \cdots \cdots \cdots & \text { D. } & 0 & (13) & 3 & \text { (11) } & 2 & \text { (14) } & 3 & \text { (11) } & 3 & \text { V. } \\ \text { right } & \cdots \cdots \cdots & \text { D. } & 0 & (16) & 4 & \text { (11) } & 5 & (12) & 4 & \text { ( } 8) & 3 & \text { V. }\end{array}$

Specimen 3 (10 $\mathrm{mm}$ long)

$\begin{array}{lllllllllllll}\text { left } & \cdots \cdots \cdots \cdots & \text { D. } & 1 & (10) & 3 & \text { (8) } & 3 & \text { (13) } & 3 & \text { (8) } & 2 & \text { V. } \\ \text { right } & \cdots \cdots \cdots & \text { D. } & 1 & (13) & 3 & (10) & 3 & (13) & 2 & (10) & 0 & \text { V. }\end{array}$

Thick and thin transverse vessels alternates rather regularly. Parastigmatic vessels: occur very sparsely. Four to seven elongate stigmata in a mesh. Tentacles ca. 20, large and small ones arranged alternately. Ciliated groove represented by a simple longitudinal slit, from which characteristic the specific name is derived.

Alimentary system: Alimentary canal situated on the postero-ventral side. It is relatively small in larger specimens, although it may occupy a half of the body length in smaller specimens. Stomach elongate, with 13-16 longitudinal striations and a minute pyloric coecum. Anus fringed with 12-20 lobules.

Gonad: Extremely small gonads are scattered rather evenly among many endocarps on the inner surface of the mantle. There are about 30 of them in total on both sides in a $25 \mathrm{~mm}$-long individual. Two testicular follicles attached to each gonad on the side of attachment of the gonad. 


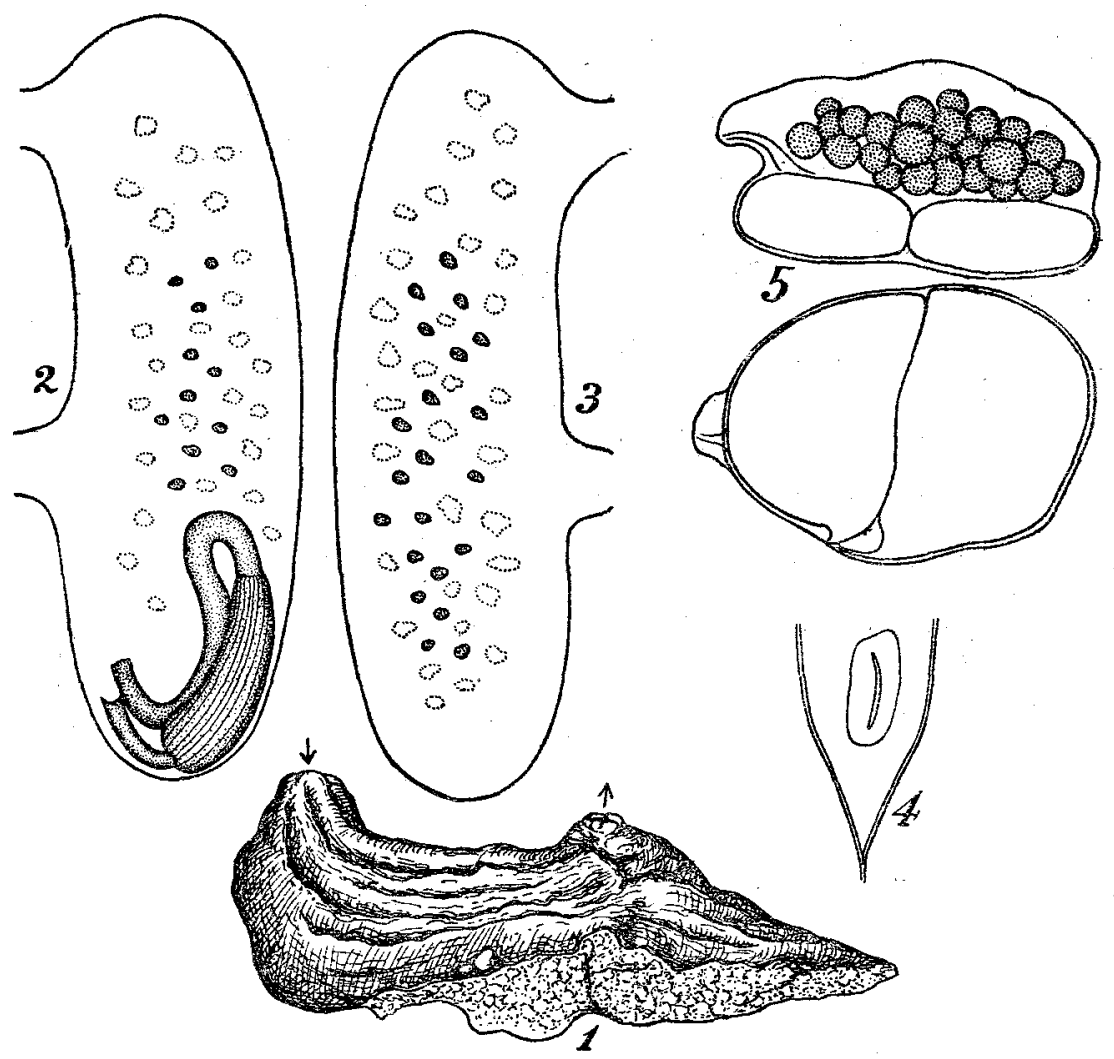

Fig. 15. Polycarpa simplex n. sp. 1-Left side of the entire animal; $2-$ Right half from inside; 3-Left half from inside; 4-Ciliated groove; 5-Gronad, $\times 110$.

Remarks: These specimens can not be considered as young individuals of $P$. captiosa, since they distinctly differ from this species in the shape and in the arrangement of the alimentary canal and also in the structure of gonad.

\section{Polycarpa cryptocarpa (SLUITER) 1885}

(Figs. 16 and 17 ; P1. X, Figs. 2 and 3 )

Many specimens, up to $80 \mathrm{~mm}$ in length. Body oval, attached by the posterior portion. Branchial aperture terminal, and atrial aperture about one-third of the body length from the anterior end of the body. Both apertures 4-lobed. Test brownish and leathery, furnished with several irregular longitudinal grooves on the surface, and coveret with many algae and other foreign matters in some specimens. It is usually $2-3 \mathrm{~mm}$ thick, although in some exceptional cases, it may reach $10 \mathrm{~mm}$ in thickness. The inner surface is grayish and glistening. Mantle purplish black, 


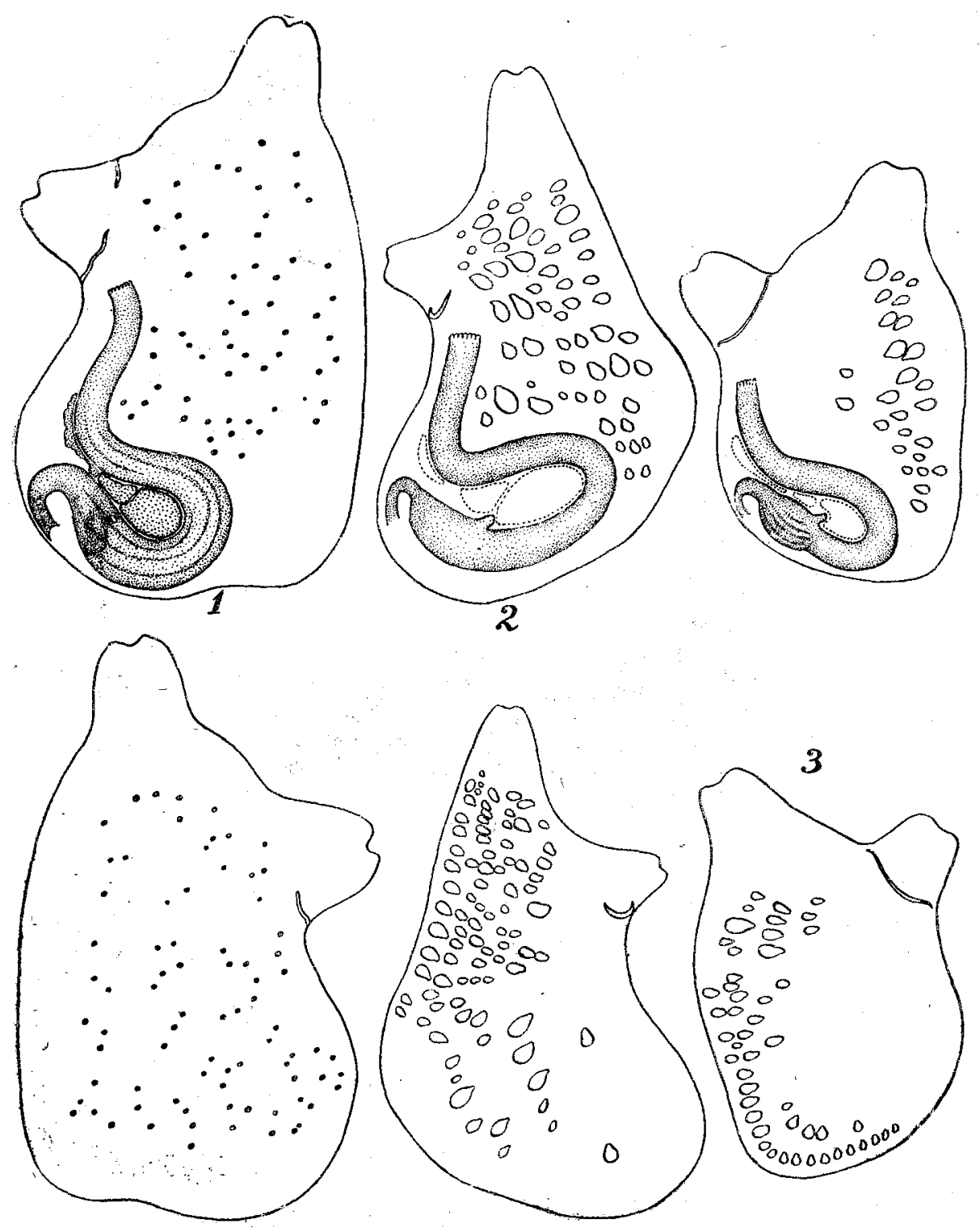

Fig. 16. Polycarpa cryptocarpa (SLutTer). 1-70 mm long individual; $2-$ $50 \mathrm{~mm}$ long individual; $3-33 \mathrm{~mm}$ long ,individual,; above left half, below right half from inside.

of ten in some individuals bearing many minute papillae on the surface. The branchial sac and alimentary canal are also purplish black. This colour is not so remarkable in young individuals as in old ones. 
Branchial sac: Arrangement of Jongitudinal vessels as follows:

Specimen 1 (70 mm long)

$$
\begin{array}{lllllllllllll}
\text { left } & \ldots \ldots \ldots \ldots & \text { D. } & 2 & (13) & 4 & (17) & 3 & (17) & 3 & (14) & 3 & \text { V. } \\
\text { right................ } & \text { D. } & 4 & (13) & 3 & (18) & 3 & (17) & 4 & (14) & 3 & \text { V. }
\end{array}
$$

Specimen 2 (50 mm long)

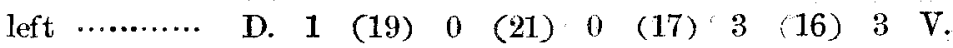

$$
\begin{aligned}
& \text { right............ D. } 2 \text { (18) } 0 \quad \text { (18) } 3 \text { (15) } 4 \text { (13) } 3
\end{aligned}
$$

Specimen 3 (33 mm long:)

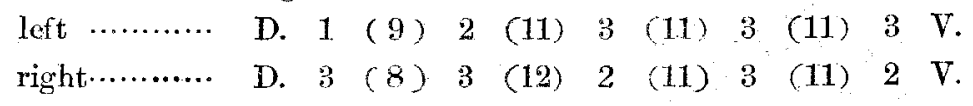

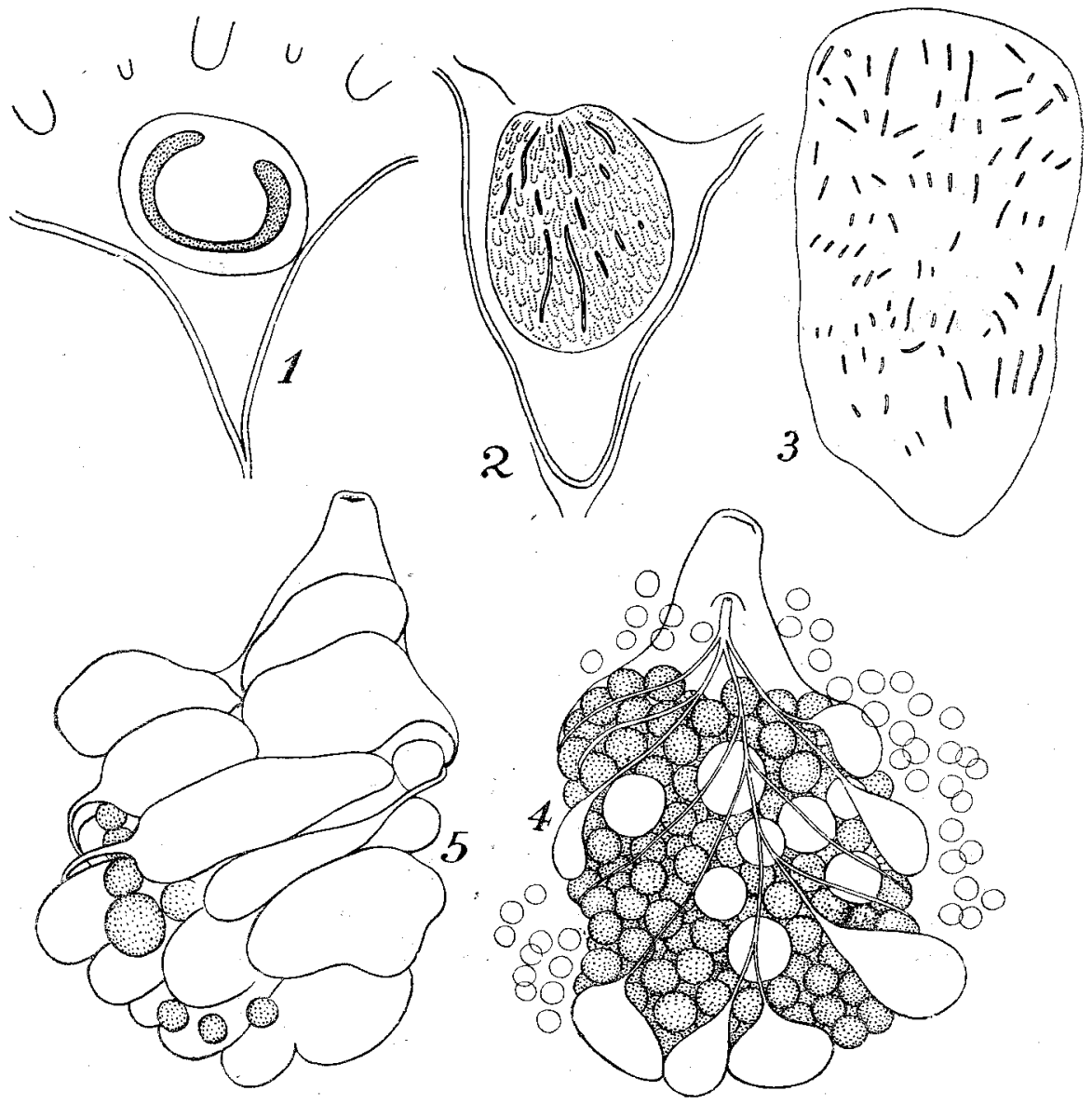

Fig. 17. Polycarpa cryptocarpa (Sluiter). 1-3-Ciliated grooves (1 $33 \mathrm{~mm}$ long, $250 \mathrm{~mm}$ long, $380 \mathrm{~mm}$ long individual); 4 \& 5-Gongd, $\times 80$. 
Three to seven thin transverse vessels between each pair of thicker vessels. A few parastigmatic vessels in the posterior part of the branchial sac. The stigmata in a mesh number 5-9 in smaller individuals, 10-13 in larger ones. Tentacles 30-55, including both large and small ones; the latter being very few. Ciliated groove simple horse-shos-shaped in smaller individuals, while it becomes more complex with age. Fig. 17-3 shows the dorsal tubercle of a $80 \mathrm{~mm}$ long individual. It is $4 \mathrm{~mm}$ in length andprovided with 81 slit-like ciliated grooves on its surface.

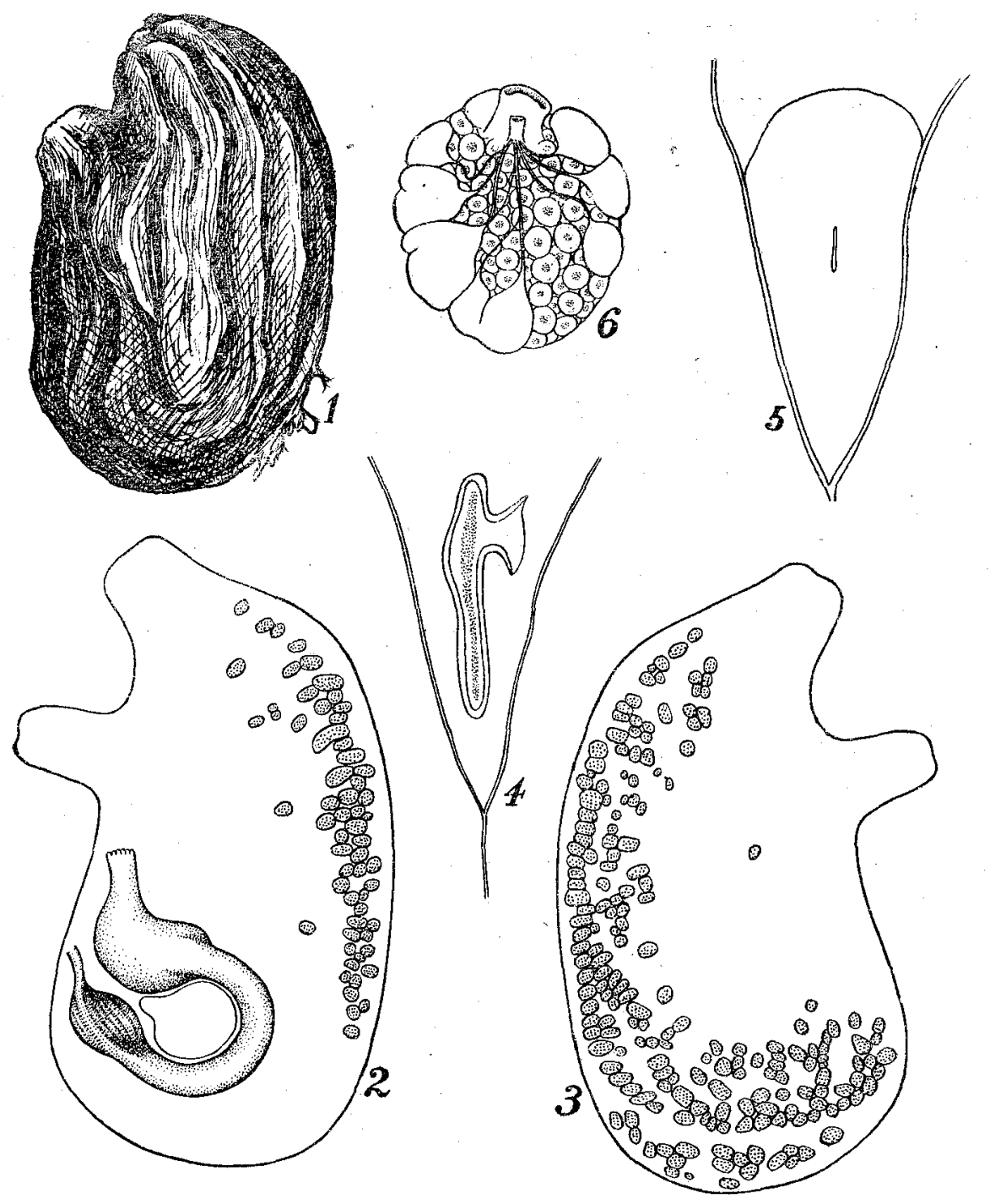

Fig. 18. Polycarpa iwayamae $n$. sp. 1-Right side of the entirènimils, 2-Left half from inside; 3-Right half from inside; $4 \& 5$-Ciliated grooves. (4 $70 \mathrm{~mm}$ long individual, $545 \mathrm{~mm}$ long individual); 6-Gonad, $\times 24$, 
Alimentary system: Stomach rather indistinct, though it is slightly thicker than the following intestine, and provided with a small pyloric coecum. Anus fringed with many lobules. A large ondo arp in the intestinal loop.

Gonad: Gonads buried in the mantle. The number of gonals is as follows:

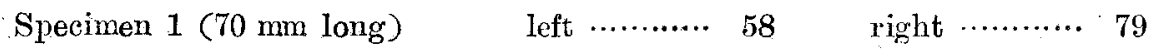

Spesimen 2 (50 mm long) left $\ldots \ldots \ldots \ldots, 56 \quad$ right $\ldots \ldots \ldots \ldots .68$

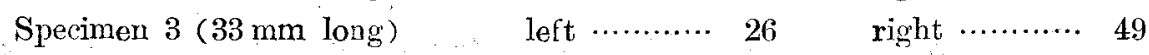

They are scattered rather evenly in larger individuals, while they are crowded densely on the ventral side in smaller ones.

\section{Polycarpa iwayamae n. sp.}

(Fig. 18)

Two specimens, one $70 \mathrm{~mm}$ long and the other $45 \mathrm{~mm}$ in length. The external and internal appearances of the body resemble closely those of the preceding species, except the following three points:-(1) the ciliated groove is very simple even in the larger specimen, (2) the stomach is devoid of pyloric coecum and the rectum has a remarkable swelling, (3) the gonads number 191 on the right and 60 on the left side in the $70 \mathrm{~mm}$ long individual, they are crowded on the ventral side. Longitudinal vessels in $70 \mathrm{~mm}$ long individual :-

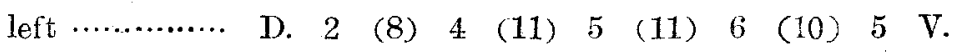

$$
\begin{aligned}
& \text { right } \cdots \ldots \ldots \ldots \text { D. } 4 \text { (9) } 4 \text { (12) } 4 \text { (12) } 5 \text { (10) } 4 \text { V. }
\end{aligned}
$$

Remarks: It is not impossible that these two specimens are merely representatives of abnormal individuals of the preceding species. I prefer, however, to treat them under a new species, since the differences mentioned above seem to be too distinct to be judged as individual variations.

\section{Polycarpa palaoensis n. sp.}

(Fig. 19)

One specimen $15 \mathrm{~mm}$ long $\times 9 \mathrm{~mm}$ wide. Branchial aperture terminal; atrial aperture slightly in front of the middle of the body. Both apertures discernible with much difficulty. Test rather thick and yellowish-white in colour, with surface divided into many small areas by irregular grooves. Mantle soft, yellowish-brown in colour.

Branchial sac: Longitudinal vessels as follows:

$$
\begin{array}{lllllllllllll}
\text { left } \ldots \ldots \ldots \ldots \ldots & \text { D. } & 0 & (8) & 2 & \text { (11) } & 1 & (13) & 1 & (7) & 0 & \text { V. } \\
\text { right } & \ldots \ldots \ldots \ldots & \text { D. } & 0 & (10) & 2 & (9) & 1 & (10) & 1 & (8) & 0 & \text { V. }
\end{array}
$$


About three small transverse vessels between each pair of larger vessels. 6-8 elongate stigmata in a mesh. Tentaeles 25, consisting mainly of large ones and partily of a few small ones. Ciliated groove S-shaped.

Alimentary system: The anterior margin of the intestinal loop reaches near the level of the atrial aperture. Stomach with ca. 6 striations on either side. Anal margin smooth.

Gonad: Gonals rather large and attached to the mantle by the posterior end, each with four testicular follicles on the side of the attachment.

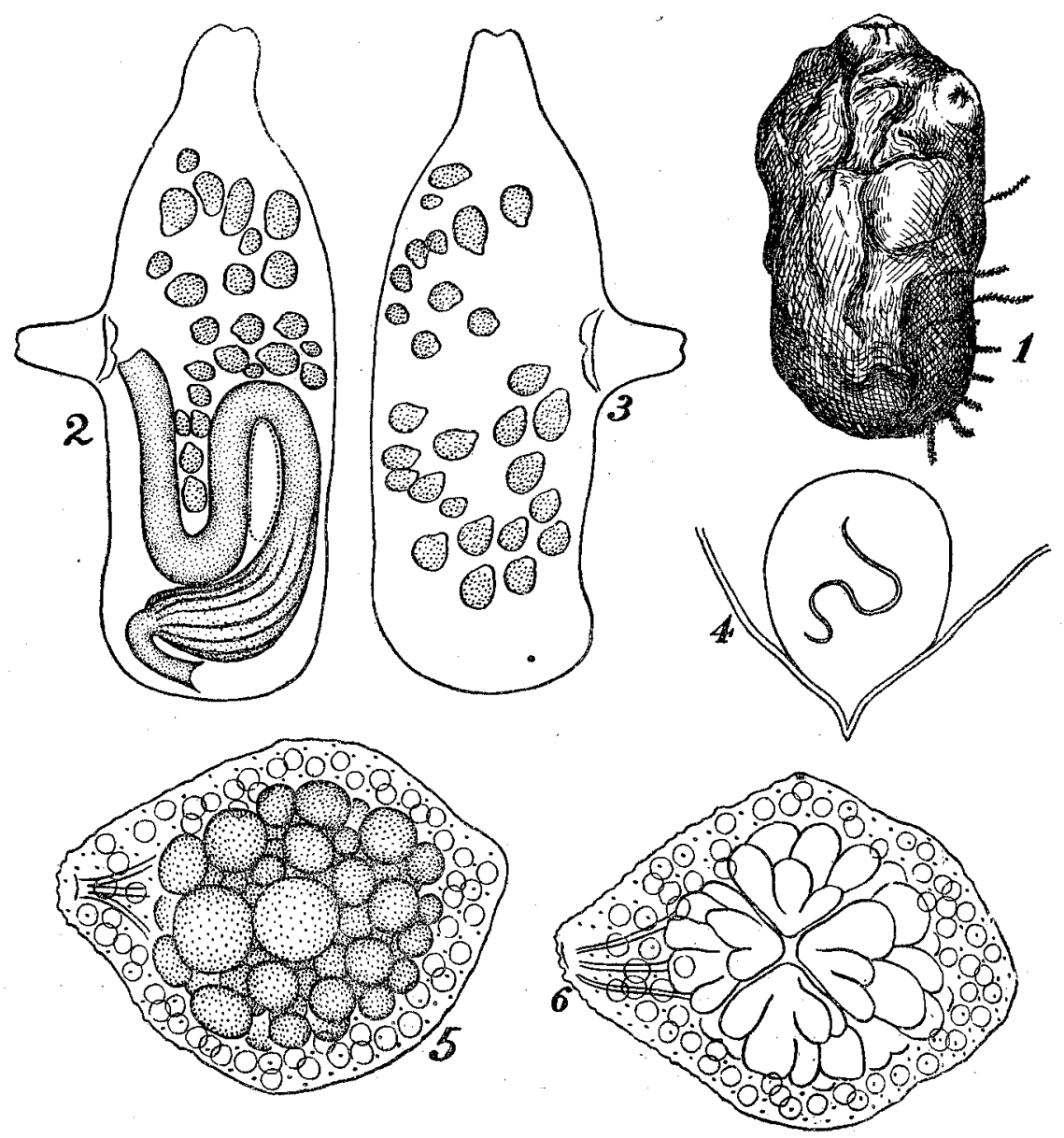

Fig. 19. Polycarpa palaoensis n. sp. 1-Left side of the entire animal; 2-Left half from inside; 3-Right half from inside; 4-Ciliated groove; 5 \& 6-Gonad, $\times 47$. 


\section{Styela' areolata HeLLER 1878}

(F.ig. 20)

Two small specimens, $13 \mathrm{~mm}$ and $17 \mathrm{~mm}$ in length, were found in the collection. External appearance resembles that of Styela plicata. Mantle brownish, very thin in the ventral half. Large endocarps present on the inper surface. Ca. 30 atrial tentacles.

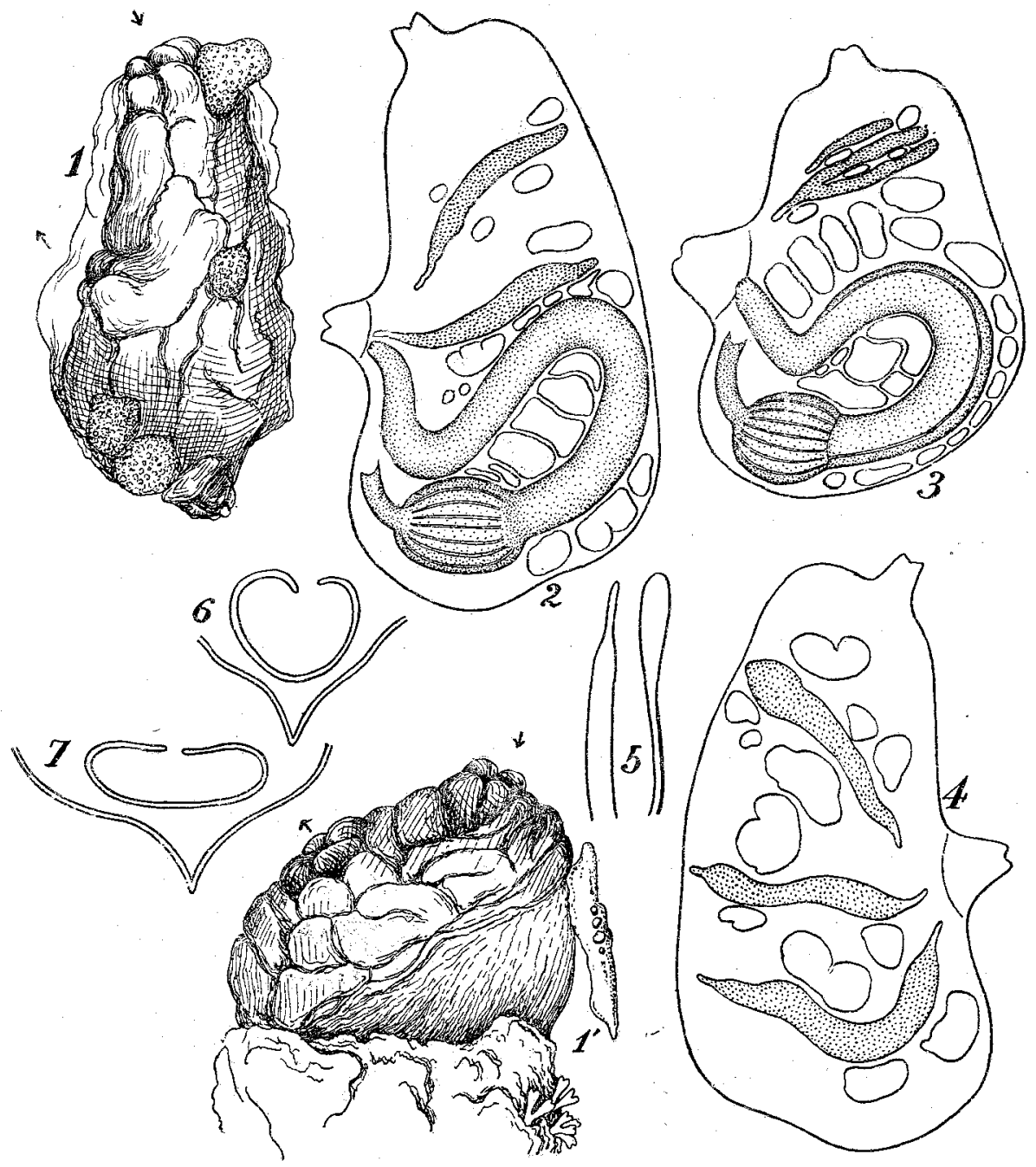

Fig. 20. Styela areolata HELLER. 1 \& $\mathbf{I}$-Right side of the entire animal (1 $17 \mathrm{~mm}$ long individual, 1' $13 \mathrm{~mm}$ long individual); 2 \& 3-Left half from inside (2 $17 \mathrm{~mm}$ long individual, $313 \mathrm{~mm}$ long individual) ; 4-Right half from inside (17 mm long individual); 5-Atrial tentacle; 6 \& 7-Ciliated grooves. 
Branchial sac: Number of longitudinal vessels as follows:

Specimen 1 (17 mm long)
left $\ldots \ldots \ldots \ldots . . . .$.
D. 1
(10) 3
(14) 3
(12) 3
(10) $2 \mathrm{~V}$.
right $\cdots . . . . .$.
D. 1
(11) 3
(13) 3
(13) 3 (11) 3 V.

Specimen 2 (13 mm long)
left $. . . \cdots \cdots . . .$.
D. 2 (9) 3
(11) 3
(12) 2
8) $2 \mathrm{~V}$.
right $\cdot \cdots \cdots \cdots$
D. 2 (9) 3
(10) 3 (10) 3
(10) $2 \mathrm{~V}$.

The scheme of transverse vessels: .........large-small-medium-small-large .........; parastigmatic vessels present. 4-5 6-7 elongate stigmata in a mesh. Tentacles $15-20$ excluding minute ones. Ciliated groove U-shaped.

Alimentary system: Stomach roundish, with eight distinct striations on each side. Pyloric coecum absent. Anus finely lobed. Several endocarps in the intestinal loop.

Gonad: Three on the right side and two or three on the left.

\section{Pyura vittata (STIMPSON) 1852}

(Fig 21)

A small, $17 \mathrm{~mm}$ long, individual found on the $45 \mathrm{~mm}$ long specimen of Polycarpa iwayamae. It is attached by its whole left side, and has a leathery test, yellowishwhite in colour. Both apertures 4-lobed. Mantle pale reddish-brown. Siphons very indistinct. Branchial aperture subterminal; atrial aperture slightly in front of the body. Both apertures fringed with red colour.
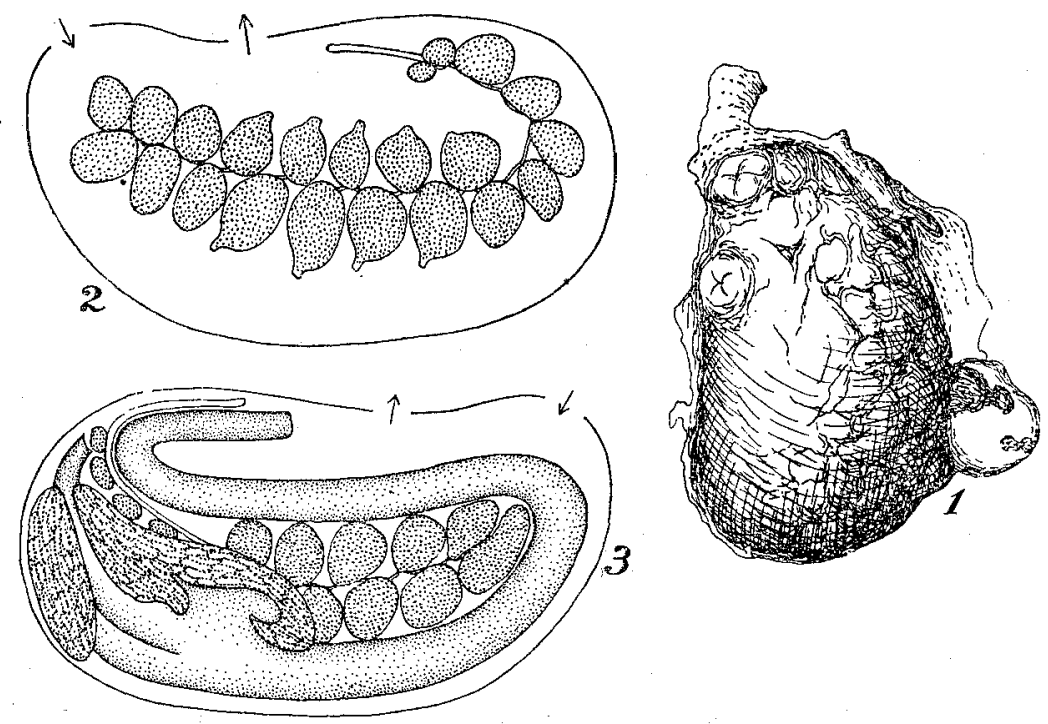

Fig. 21. Pyura vittata (STrmpson). 1--Right side of the entire animal; 2Right half trom inside; 3- Left half from inside. 
Branchial sac: Longitudinal vessels as follows:

$\begin{array}{lllllllllllllllll}\text { left } & \cdots \cdots & \text { D. } & 1 & (15) & 2 & (14) & 3 & (15) & 5 & (14) & 5 & (11) & 4 & (9) & 3 & \text { V. } \\ \text { right } \cdots \cdots & \text { D. } & 1 & (16) & 2 & (16) & 3 & (16) & 3 & (15 & 5 & (13) & 5 & (9) & 2 & \text { V. }\end{array}$

Parastigmatic vessels present. 3-5 stigmata in a mesh. Tentacles ca. 20; branches in 2 orders, those of the sec ond order being rudimentary. Ciliated groove $\mathbf{U}$-shaped.

Alimentary system: Gastric portion is somewhat thicker than the following intestinal canal. Liver yellowish. Anus not lobed.

Gonad: As in common pyurids.

Remarks: The whitish test, the swollen gastric portion, the absence of siphon and the attachment by whole left side are the characteristics of this specimen, which differentiate it from the typical $P$. vittatd. These features, however, can be attributed to the differences in age or to the condition of contraction.

\section{Pyura curvigona n. sp.}

(Fig. 22 ; Pl. X, Figs. 4-6)

Three specimens; the largest one of which is $50 \mathrm{~mm}$ in length. Body oval to elongate, attached by large part of the ventro-sinistral side. In large specimens, branchial aperture terminally situated and atrial aperture close to it. Both apertures. 4-lobed. Test leathery and yellowish white, with many grooves and folds on the surface. Mautle yellowish brown; strong muscles found only in the anterior half of the body. Inner surface of siphons bright red.

Branchial sac: Six folds on each side. Longitudinal vessels as follows:

Specimen 1 (50 $\mathrm{mm}$ long)

$$
\begin{array}{ccccccccccccccc}
\text { left........D. } & 4 & (\mathbf{1 9}) & 4 & (\mathbf{1 9}) & 4 & (\mathbf{1 9}) & 5 & (20) & 5 & (17) & 5 & (\mathbf{1 1}) & 5 & \text { V. } \\
\text { right.....D. } & 3 & (18) & 4 & (18) & 6 & (\mathbf{2 1}) & 5 & (19) & 7 & (17) & 6 & (13) & 5 & \text { V. }
\end{array}
$$

Specimen 2 (25 $\mathrm{mm}$ long)

$$
\begin{array}{lllllllllllllll}
\text { left.........D. } & 3 & (19) & 4 & (18) & 4 & (19) & 4 & (19) & 5 & (15) & 5 & (13) & 6 & \text { V. } \\
\text { right …...D. } & 4 & (17) & 3 & (17) & 4 & (20) & 4 & (18) & 4 & (18) & 6 & (14) & 5 & \text { V. }
\end{array}
$$

Two to three thin transverse vessels between each pair of thicker ones. Parastigmatic vessels present. Three to five elongate stigmata in a mesh. Tentacles ca. 15, excluding minute ones; of which 10 are very large; branches in 2 orders. Ciliated groove U- or S-shaped.!

Alimentary sys'em: The anterior margin of the intestinal loop reaches the level of the atrial aperture, but never beyond it. Rectum strongly swollen at the bending point of the 2nd loop. Anus fringed with lobules. Liver whitish or olive green; hepatic lobules very loosely crowded and occupying a wide area. A fow rudimentary lobules are found on the cardiac portion of the stomich in the $50 \mathrm{~mm}$ long individual. Endocarps arranget along the alimentary canal. 

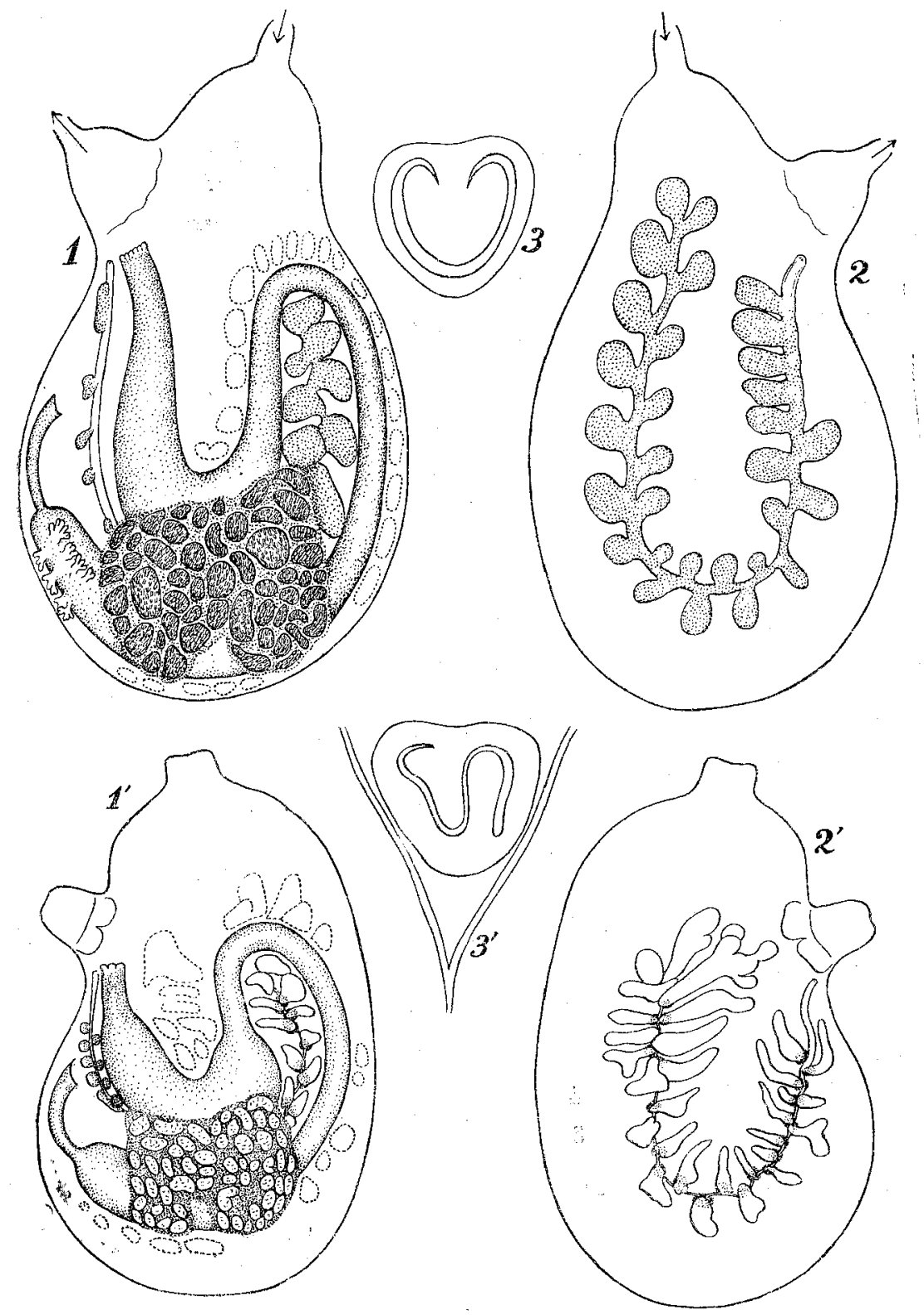

F'ig 22. Pyura curvigona n. sp. 1 \& 1 -Left half from inside"; $2 \& 2$ Right half from inside; 3 \& 3 -Ciliated grooves. (1-3 50 mm long individual $1^{\prime}-3^{\prime} \quad 25 \mathrm{~mm}$ long individual).

Gonad: Characteristic U-shaped.

Remarks: The present new species closely resembles $P$. villata, but it is certain that this represents a distinct species. 


\section{Pyura subuculata (SLUITER) 1900}

(Fig. 23, 1-4; P1. X, Fig. 7)

A small specimen, $18 \mathrm{~mm}$ long, attached on an alcyonarian by its ventro-sinistral side. Body ovoid; branchial aperture subterminal, atrial aperture slightly behind the middle of the body. Test leathery, brownish yellow in colour and finely wrinkled. The area between both apertures is irregularly folded and reddish. The inner side grayish white. Mantle brown; muscles present only in the dorsal half. Siphons contracted. Atrial velum well developed.

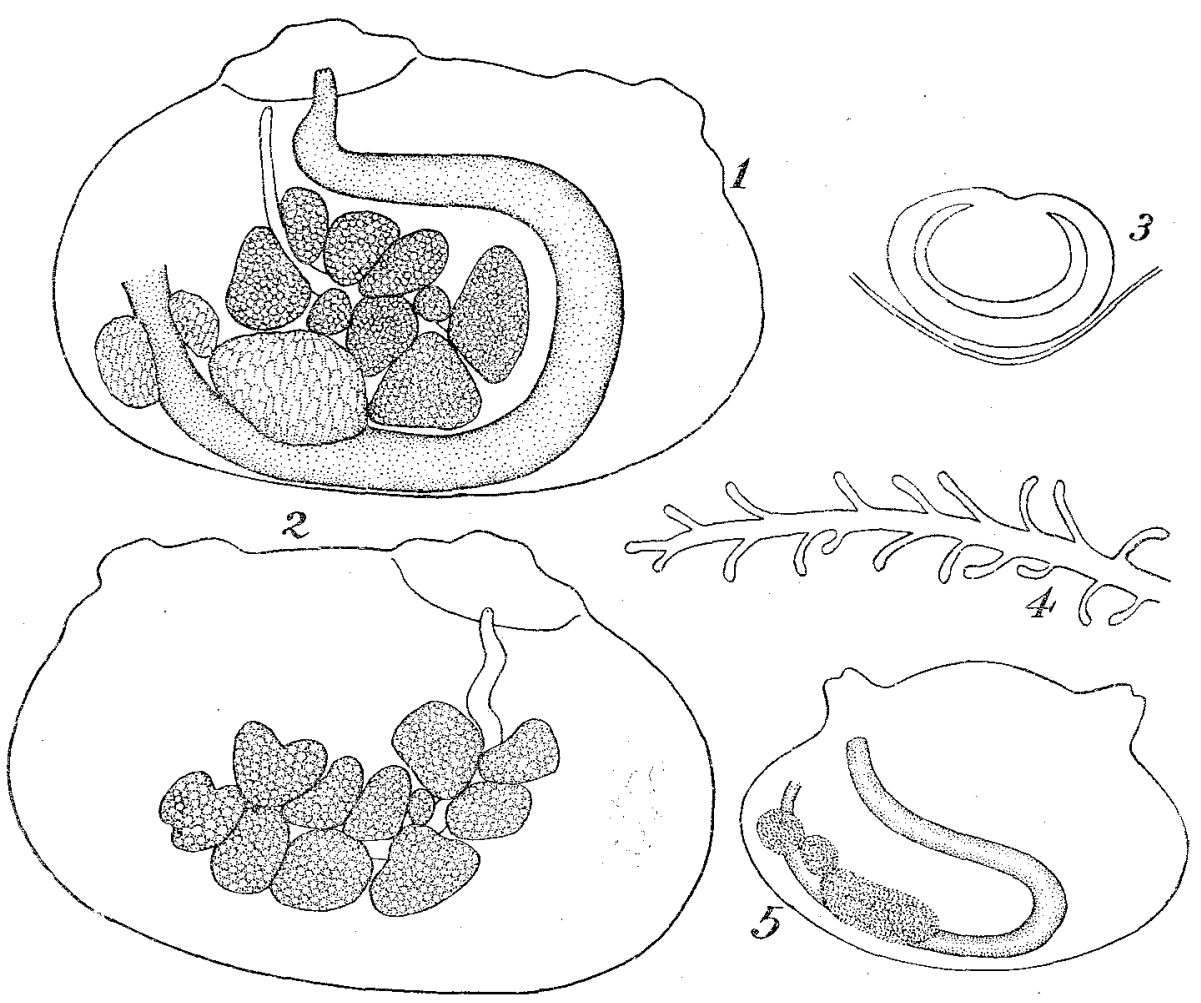

Fig. 23. 1-4 Pyura subuculata (SLUITER). 5 Herdmana momus (SAVI GNY) 1-Left half from inside; 2-Right half from inşide; 3 -Ciliated groove; 4-Tentacle, $\times 24 ; 5-$ Left half from inside.

Branchial sac: Seven folds on each side. Longitudinal vessels as follows:

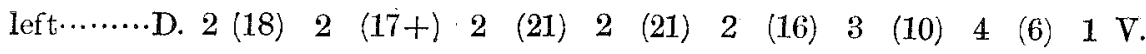

$$
\begin{aligned}
& \text { right….. D. } 2 \text { (17) } 2 \text { (20) } 2 \text { (25) } 2 \text { (23) } 2 \text { (19) ? (?) ? (8) } 1 \text { V. }
\end{aligned}
$$


Three thin transverse vessels between each pair of thicker ones. Parastigmatic vessels present. Three to four elongate stigmata in a mesh. Tentacles 31, consisting of large and small ones; they are slender and marked with conspicuous yellowish pigments; branches in one order. Ciliated groove U-shaped.

Alimentary system: Intestinal loop very wide and open. Liver yellowish brown and divided into three lobes. Margin of anus fringed with 5 lobes.

Gonad: As in common pyurids.

Remarks: Differences found between the present specimen and SLuITER's specimen from French Pass in the length of siphons and in the number of stigmata in a mesh seem to be within the range of individual variations. This species resembles closely $P$. shiinoi [Tokıoka (1949): Publ. Seto Mar. Biol. Lab., I, 2, pp. 59-61] which has, however, a closed intestinal loop and two hepatic lobes widely departed from each other.

\section{Herdmania momus (SAVIGNY) 1816}

(Fig. 23-5)

I record here merely the formula of longitudinal vessels of the branchial sac of a young $11 \mathrm{~mm}$ long individual :
left.
D. 1 (8) 1
(10) 1
(13) 1
(14) ?
(13) ?
(10) 0
(6) $0 \quad$ (2) $0 \mathrm{~V}$.
right ......
D. $0(6), 1$
(12) 1
(14) 1 (14)
(12) 1
(10) 0
(5) 0
(3) $1 \mathrm{~V}$.

Gonad is not yet developed in this specimen. Liver is already divided into three, two small and a larger lobes, as in grown individuals.

\section{EXPLANATION OF PLATE IX}

Fig. $1 \cdots .$. Ascidia minuta n. sp., larva, $\times 80$.

Fig. 2…Ascidia gemmata SLuITER, right side of the animal.

Fig. $3 \cdots \cdots$ Ascidia sydneiensis STIMPSON,

Fig. 4......Phallusia julinea Sturter, 


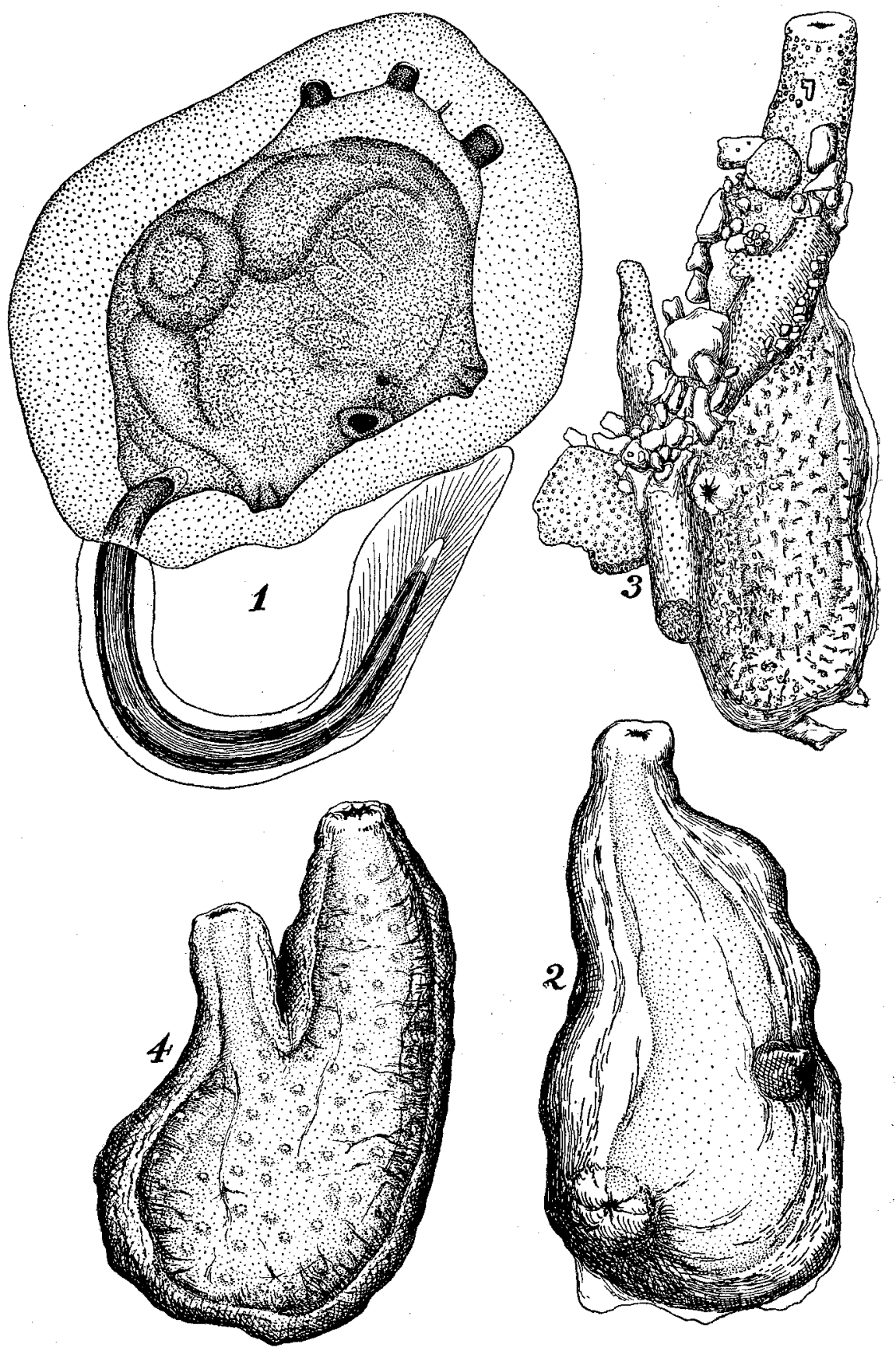

T. Tokioka : Ascidians from the Palao Islands, I 


\section{EXPLANATION OF PLATE $\mathrm{X}$}

F'ig. 1….Polycarpa captiosa (SLuiter), right side of the animal.

Fig. 2…Polycarpa cryptocarpa (SLUITER),

(70 mm long individual).

Fig. $3 \cdots \cdots, \quad, \quad$,

(33 mm long" individual).

Fig. $4 \cdots \cdots \cdot$. Pyura curvigona n. sp.,

(25 mm long" individual).

Fig. $5 \cdots . ., \quad, \quad$ (50 $\mathrm{mm}$ long" individual).

Fig. $6 \cdots . . . \quad$ " $\quad$ (17 $\mathrm{mm}$ long" individual).

Fig. 7.....Pyura subuculata (SLUITER), right side of the animal. 
Publ. Seto Mar. Biol. Lab., I, 3 (1950)

PIATE X
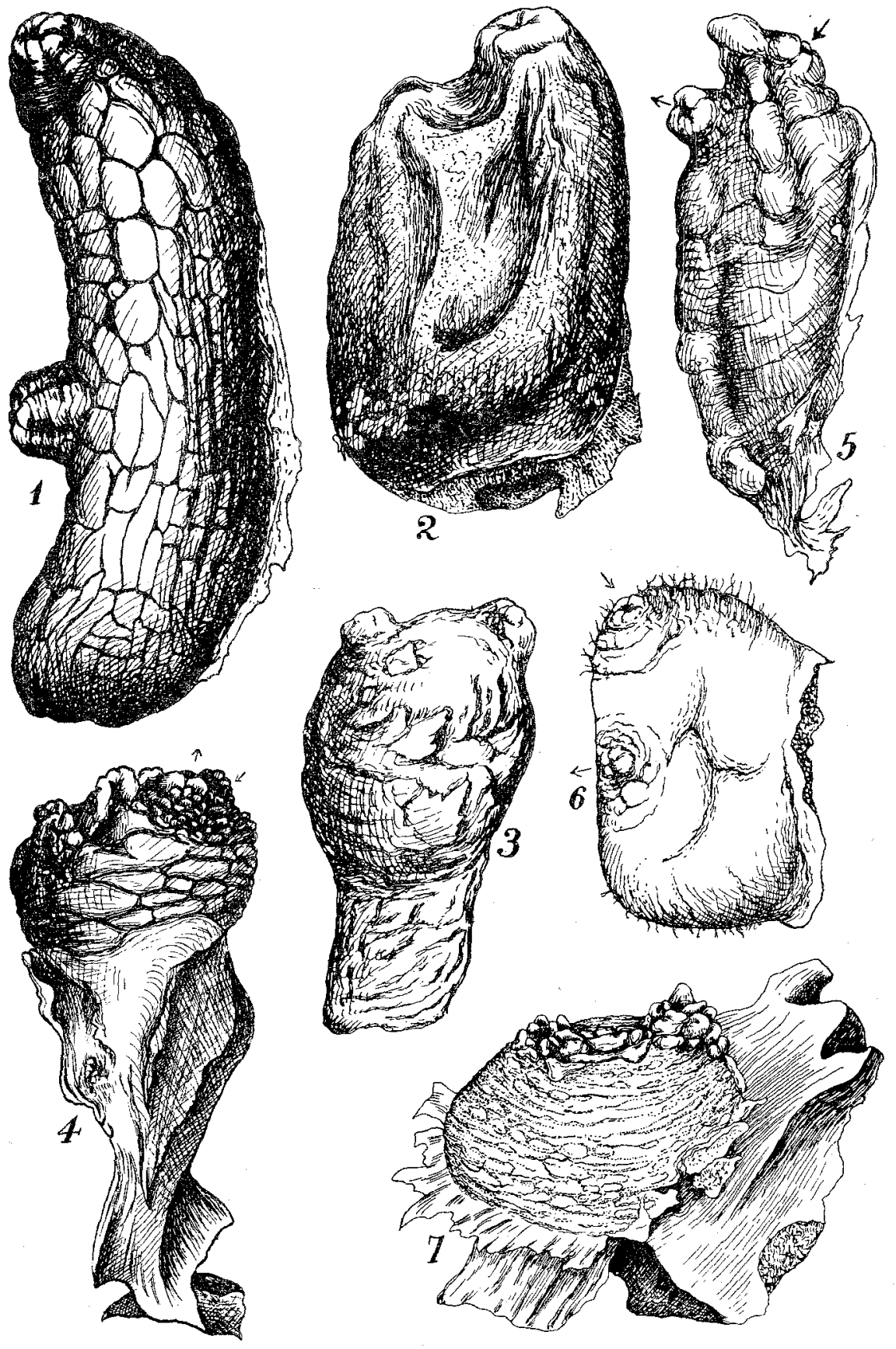

T. Tokioka: Ascidians from the Palao Istands, I 